Neurosurg Focus 19 (5):E3, 2005

\title{
Molecular genetics of supratentorial primitive neuroectodermal tumors and pineoblastoma
}

\author{
Mei Hua Li, Ph.D., Eric Bouffet, M.D., Cynthia E. Hawkins, M.D., Ph.D., \\ Jeremy A. Squire, Ph.D., And Annie Huang, M.D., Ph.D. \\ Arthur and Sonia Labatt Brain Tumor Research Centre, Cancer Research Program, Division of \\ Hematology and Oncology, and Department of Pediatric Laboratory Medicine, Hospital for Sick \\ Children, Toronto; Ontario Cancer Institute, Toronto; and Department of Pathobiology and \\ Laboratory Medicine, University of Toronto, Ontario, Canada
}

\begin{abstract}
The supratentorial primitive neuroectodermal tumors (PNETs) are a group of highly malignant lesions primarily affecting young children. Although these tumors are histologically indistinguishable from infratentorial medulloblastoma, they often respond poorly to medulloblastoma-specific therapy. Indeed, existing molecular genetic studies indicate that supratentorial PNETs have transcriptional and cytogenetic profiles that are different from those of medulloblastomas, thus pointing to unique biological derivation for the supratentorial PNET. Due to the rarity of these tumors and disagreement about their histopathological diagnoses, very little is known about the molecular characteristics of the supratentorial PNET. Clearly, future concerted efforts to characterize the molecular features of these rare tumors will be necessary for development of more effective supratentorial PNET treatment protocols and appropriate disease models. In this article the authors review existing molecular genetic data derived from human and mouse studies, with the aim of providing some insight into the putative histogenesis of these rare tumors and the underlying transforming pathways that drive their development. Studies of the related but distinct pineoblastoma PNET are also reviewed.
\end{abstract}

\author{
KEY WoRDS - supratentorial primitive neuroectodermal tumor • pineoblastoma • \\ molecular genetics
}

\section{OVERVIEW}

The supratentorial PNET and pineoblastoma are highgrade, relatively undifferentiated tumors arising from the cerebral hemispheres and the pineal regions, respectively. Although they are histologically very similar to medulloblastoma, supratentorial PNETs have markedly different clinical behavior and are generally considered to represent a more aggressive tumor group than medulloblastoma, with a frequently massive tumor burden and a higher incidence of disseminated disease at diagnosis, as reviewed in Jakacki. ${ }^{85}$ Because cerebral supratentorial PNETs may often be deep-seated in paraventricular, thalamic, and hypothalamic sites, ${ }^{44}$ they pose significant challenges to safe resection and the delivery of limited radiation. Thus, despite their smaller numbers, supratentorial PNETs are a significant therapeutic problem because these highly aggressive, therapyresistant tumors primarily affect younger children, who are the most likely to suffer long-term damage due to radiation.

Existing data support the suggestion that supratentorial

Abbreviations used in this paper: $\mathrm{cdk}=$ cyclin-dependent kinase; $\mathrm{CGH}=$ comparative genomic hybridization; $\mathrm{CNS}=$ central nervous system; mRNA = messenger RNA; PNET = primitive neuroectodermal tumor; $\mathrm{Shh}=$ Sonic hedgehog; $\mathrm{WHO}=$ World Health Organization.
PNETs have molecular features that are unique from those of medulloblastoma. Nevertheless, because of the rarity of supratentorial PNETs, only limited molecular studies of small numbers of supratentorial PNETs have been conducted to date. Clearly, comprehensive knowledge of the molecular genetic features of supratentorial PNETs will be essential in future studies to advance diagnosis, therapy, and prognosis in this rare but challenging tumor group. We review existing molecular studies of supratentorial PNETs with a view to improving our current understanding of putative signaling defects and molecular abnormalities in supratentorial PNETs. We also review molecular studies of pineoblastomas, a $\mathrm{WHO}^{94}$ Grade IV pineal parenchymal tumor that has often been considered collectively with the supratentorial PNET in molecular and therapeutic studies. Nevertheless, existing data suggest distinct histogenesis and unique molecular genetics for the pineoblastoma, and they are therefore discussed separately.

\section{SUPRATENTORIAL PNETS}

Collectively, supratentorial PNETs are relatively rare, representing approximately one tenth the frequency of medulloblastoma, and 3 to $7 \%$ of pediatric CNS tumors. ${ }^{91,97}$ They 
are diagnosed at a younger median age than medulloblastomas; more than $65 \%$ of supratentorial PNETs are reported in patients younger than 5 years of age with no significant sex predominance (reviewed in Jakacki, et al. ${ }^{86}$ ). In a Pediatric Oncology group trial for delayed radiation in children younger than 3 years of age, supratentorial PNETs represented the second most common tumor (13 of 19). ${ }^{44}$ Supratentorial PNETs can present as congenital tumors. ${ }^{39,64,113} \mathrm{Al}-$ though supratentorial PNET is generally considered almost exclusively a pediatric tumor, rare adult series have been described. ${ }^{91,155}$ There is currently insufficient literature to judge whether supratentorial PNETs in adults differ from those in children. It is notable, however, that one study reported a 3-year survival rate of $75 \%$ for a series of 12 patients, a rate far superior to any reported in pediatric supratentorial PNETs. ${ }^{91}$ These observations, together with reports of a high frequency of p53 mutations in adult supratentorial PNETs ${ }^{74}$ suggest they are likely to represent distinct diseases.

High-grade glial tumors are well recognized as potential late complications of the craniospinal radiation treatment used in childhood leukemias. Interestingly, supratentorial PNETs can also present as secondary malignancies after therapy for hematological as well as primary intracranial neoplasms. To date, seven cases of secondary supratentorial PNET arising after treatment for childhood acute lymphocytic leukemia, acute myeloid leukemia, or lymphoma have been reported. ${ }^{102}$ Secondary supratentorial PNETs have been reported in the context of cancer predisposition syndrome in two patients. One child presented with supratentorial PNET 5 years after treatment for unilateral retinoblastomas,,$^{50}$ and in another with neurofibromatosis Type 1, supratentorial PNET developed after radiation treatment for a brainstem astrocytoma. ${ }^{132}$ Supratentorial PNETs can also occur as secondary malignancies in both children and adults with no genetic condition. Tumors occurring up to 18 years after radiation treatment for low-grade primary intracranial neoplasms such as cerebellar pilocytic astrocytoma and low-grade astrocytoma have been described. . $^{34,69}$

A supratentorial PNET most commonly arises in the cerebrum, and is seen less frequently in deep paraventricular or midline locations such as the diencephalon and basal ganglia. ${ }^{47}$ Rarely, PNETs can present in the leptomeninges without evidence of primary tumor in the supra- or infratentorial compartments. ${ }^{13}$ These are proposed to arise from heterotopic glial nests within the subarachnoid space; ${ }^{41}$ however, their true histogenesis and their relationship to either medulloblastoma or supratentorial PNET is unknown.

The current literature contains reports suggesting that metastatic disease, extent of surgery, and age at diagnosis may be of prognostic relevance in supratentorial PNETs. ${ }^{3,75,135}$ Based on more aggressive clinical features, supratentorial PNETs have traditionally received therapies designed for metastatic, high-risk medulloblastomas, which involves more intensive chemotherapy and higher doses of radiation to the head and spine. Several retrospective ${ }^{123,135}$ and prospective studies $40,75,86$ have consistently reported significantly inferior outcomes for even localized supratentorial PNETs treated with high-risk medulloblastoma therapy. To date, the overall survival rate for supratentorial PNETs is substantially lower than that for medulloblastomas, with an expected 3year progression-free survival of approximately $50 \%$ for localized supratentorial PNETs. ${ }^{75,135}$ These observations sug- gest intrinsic biological differences between supratentorial PNET and medulloblastoma.

\section{Histopathological Diagnosis of Supratentorial PNET}

Histopathological classification of supratentorial PNET remains a contentious issue. Based on the indistinguishable histological features of supratentorial PNET and medulloblastoma, a common histopathological grouping of all PNETs with a presumed common histogenesis was proposed $^{140}$ and remains disputed. ${ }^{109}$ Current WHO criteria identify supratentorial PNET as a Grade IV tumor with undifferentiated or poorly differentiated neuroepithelial cells, and with the capacity for divergent differentiation along multiple lineages, including neuronal, astrocytic, ependymal, muscular, or melanocytic lines. ${ }^{142}$ Because specific marker(s) for supratentorial PNET do not exist, these lesions are still diagnosed primarily on the basis of a supratentorial location and histological features of a predominantly undifferentiated neuroepithelial tumor with focal areas of divergent differentiation. The inclusion of supratentorial neuronal tumors with more distinct neuronal differentiation, such as the cerebral neuroblastoma, or the ganglioneuroblastoma with its distinct ganglionic features, remains controversial. ${ }^{12,14}$ When supratentorial PNETs demonstrate very little morphological or immunohistochemical signs of differentiation, they pose diagnostic challenges with respect to other high-grade supratentorial tumors such the "round" or "small cell" glioblastoma variants, which may also exhibit a similarly undifferentiated phenotype. ${ }^{94}$ For polyphenotypic supratentorial PNETs presenting in a young child with expression of epithelial or muscular antigens such as epithelial membrane antigen and smooth-muscle actin, the differentiation from the highly aggressive CNS rhabdoid tumors ${ }^{141}$ may pose significant challenges, because INII mutation has been reported in supratentorial tumors without typical histological "rhabdoid" features. ${ }^{150}$

In a recent survey, pathologists identified histopathological diagnosis of supratentorial PNET as an area of significant challenge. ${ }^{7}$ The continuing uncertainties about the precise histological criteria required for diagnosis and the relative rarity of these tumors means that published genetic and molecular genetic data, particularly in small series, may be difficult to interpret, and may have included highgrade neuroglial and neuroepithelial tumors whose histiogenetic relationships to supratentorial PNETs were uncertain. Nonetheless, molecular cytogenetic data compiled so far suggest that supratentorial PNETs collectively exhibit changes that differ from those of the infratentorial medulloblastoma, ${ }^{115,146}$ and support the development of supratentorial PNETs from biological pathways distinct from those involved in medulloblastoma development.

\section{Cytogenetic and Molecular Genetic Alterations in Human Supratentorial PNETs}

In contrast to medulloblastomas, very few cytogenetic and molecular genetic studies of human supratentorial PNETs are available. To date, karyotypic studies of only 22 pediatric supratentorial PNETs arising in the cerebrum have been reported as part of larger collective series on medulloblastomas and PNETs $1,11,15,21,30,32,61,139,162$ (Table 1). Supratentorial PNETs frequently show complex karyotypes, with evidence of double minutes structures associated with high- 
TABLE 1

Literature review and summary of published karyotypes for supratentorial PNETs*

\begin{tabular}{|c|c|c|c|c|}
\hline Authors \& Year & $\begin{array}{l}\text { Tumor } \\
\text { No. }\end{array}$ & $\begin{array}{l}\text { Age (yrs), } \\
\text { Sex }\end{array}$ & Location & Karyotype \\
\hline \multirow[t]{3}{*}{ Chadduck, et al., 1991} & 16 & $<1$ & & normal \\
\hline & 17 & $<1$ & & normal \\
\hline & 19 & $<1$ & & $45, X Y,-22$ \\
\hline \multirow[t]{2}{*}{ Fujii, et al., 1994} & 7 & $9, \mathrm{~F}$ & normal & \\
\hline & 8 & $14, \mathrm{M}$ & & normal \\
\hline Agamanolis \& Malone, 1995 & 1 & $9, \mathrm{~F}$ & frontal & normal \\
\hline Bhattacharjee, et al., 1997 & 6 & & & parietal $\quad 46, X Y, i(1)(q 10) ;-9, t(9 ; 11)(q 34 ; q 13)<8 ? / 90 ;$ idemx2, $-X, Y^{1} / 46 ; X Y$ \\
\hline \multirow[t]{4}{*}{ Bigner, et al., 1997} & 2 & $2, \mathrm{M}$ & & $46, \mathrm{XY}, \mathrm{t}(6: 9)(\mathrm{q} 21 ; \mathrm{q} 13), \operatorname{del}(10)(\mathrm{q} 22)^{2} / 45$. idem, $\mathrm{t}(11 ; 13)(\mathrm{q} 15 ; \mathrm{q} 11)-13^{3}$ \\
\hline & 3 & & & normal \\
\hline & 4 & & & normal \\
\hline & 5 & & & normal \\
\hline \multirow[t]{3}{*}{ Bayani, et al., 2000} & 10 & 3 & & 70-103 chromosome, double ring, and dmins \\
\hline & 11 & 2 & & $46, X Y, t(6 ; 13)(q 25 ; q 14)$ \\
\hline & 12 & 3.5 & & 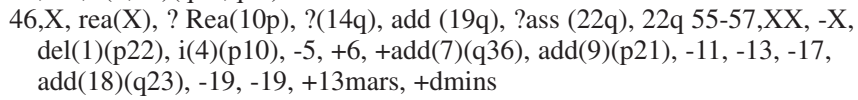 \\
\hline \multirow[t]{3}{*}{ Roberts, et al., 2001} & 13 & & cerebral & 46,XX,del(2)(p22.2-2p23.1) del(5)(q33.35)/46, idem, del(17)(q21.3q21.3), \\
\hline & 14 & & parietooccipital & $\begin{array}{l}\operatorname{der}(9: 15)(\mathrm{q} 10 ; \mathrm{q} 10) \times 2,+11,+13,+18,+20,+2056 \sim 59, \mathrm{Xc},+\mathrm{X},+1,+1,+1, \\
\quad \operatorname{add}(1)(\mathrm{p} ?), \operatorname{add}(1)(\mathrm{q} ?),+2, \operatorname{del}(2)(\mathrm{p} 24),+7,+8, \operatorname{add}(8)(\mathrm{q} ?)\end{array}$ \\
\hline & 15 & & parietal & $\begin{array}{l}\text { 69 75XX, -X, add (10(q42)x2,-4,-4, add(4)(q3?), -10, -11, del(11)(q2?), } \\
-13,-16,-18,+7 \sim 13 \operatorname{mar}, \operatorname{dmin}(\mathrm{cp} 7) \mathrm{dmins}\end{array}$ \\
\hline Uematsu, et al., 2002 & 20 & 7 & insular cortex & $52, \mathrm{XX},+1 \mathrm{X} 2, \operatorname{add}(3)(\mathrm{q} 25)+7 \mathrm{X} 2, \operatorname{add}(11)(\mathrm{q} 25) \mathrm{X} 2,+21 \mathrm{X} 2$ \\
\hline
\end{tabular}

* Dmin = double minute.

$\dagger$ Secondary malignancy after acute lymphocytic leukemia therapy.

level gene amplification. Interestingly, eight of 19 reported cases had normal karyotypes. In one series of four infants with supratentorial PNET, three cases had normal karyotypes, whereas one case had monosomy ${ }^{22}$ as the sole cytogenetic abnormality, ${ }^{32}$ indicating that subtle genetic changes may be characteristic of a substantial proportion of supratentorial PNETs. Complex karyotypes in 10 of 19 cases involved mostly structural changes with interstitial deletions, partial chromosome gains, and translocations involving a number of different chromosomes. Recurrent regions of cytogenetic alterations included deletions or translocations involving chromosome 10q22-26 in three of 10 cases, and translocations involving chromosome 6q2125 in two of 10.

Notably, one patient (Case 11 in Table 1) had a translocation involving chromosome $6 \mathrm{q} 25$ and chromosome $13 q 14$ as the sole cytogenetic abnormality (this was a child with no history of retinoblastoma). ${ }^{11}$ The finding of this sole abnormality, also confirmed by the authors using high-resolution spectral karyotyping analyses, implies involvement of the RB1 locus on chromosome 13q14, and a putative novel supratentorial PNET oncogene or tumor suppressor gene at chromosome 6q21-25. No data were available on the constitutional DNA of this patient. Double minutes, indicative of high-level gene amplification, were seen in three of 18 cases, a frequency comparable to that reported for medulloblastoma. ${ }^{16,21}$

\section{Comparative Genomic Hybridization Studies}

The CGH profiles of 16 supratentorial PNETs (five of which were found in adults but not separately identified $)^{8,11}$, $30,115,146$ are summarized in Fig. 1. Not surprisingly, these higher-resolution analyses indicate a greater frequency of genomic imbalances than appreciated on karyotypic studies, with only one of 16 supratentorial PNETs being reported as normal based on results of CGH. Existing data indicate that supratentorial PNETs differ from medulloblastomas in the pattern and frequency of DNA copy number changes. Most significantly, chromosome 17p loss, which characterizes many medulloblastomas, ${ }^{19,30,131}$ is rare in supratentorial PNETs. In up to $40 \%$ of medulloblastomas, a characteristic isochromosome 17 , which results from concurrent gain of chromosome $17 q$ and loss of $17 p$, is observed. ${ }^{20}$ In contrast, although gain of $17 \mathrm{q}$ or the entire chromosome 17 is seen in supratentorial PNET, isochromosome 17 has only been reported in one case of supratentorial PNET. ${ }^{146,175}$ So far, allelotyping studies have disclosed loss of chromosome $17 \mathrm{p}$ in only one of 36 primary supratentorial PNETs ${ }^{11,23,30,99,131}$ and one supratentorial PNET cell line. ${ }^{62}$ In addition, epigenetic changes at a breakpoint cluster 
M. H. Li, et al.

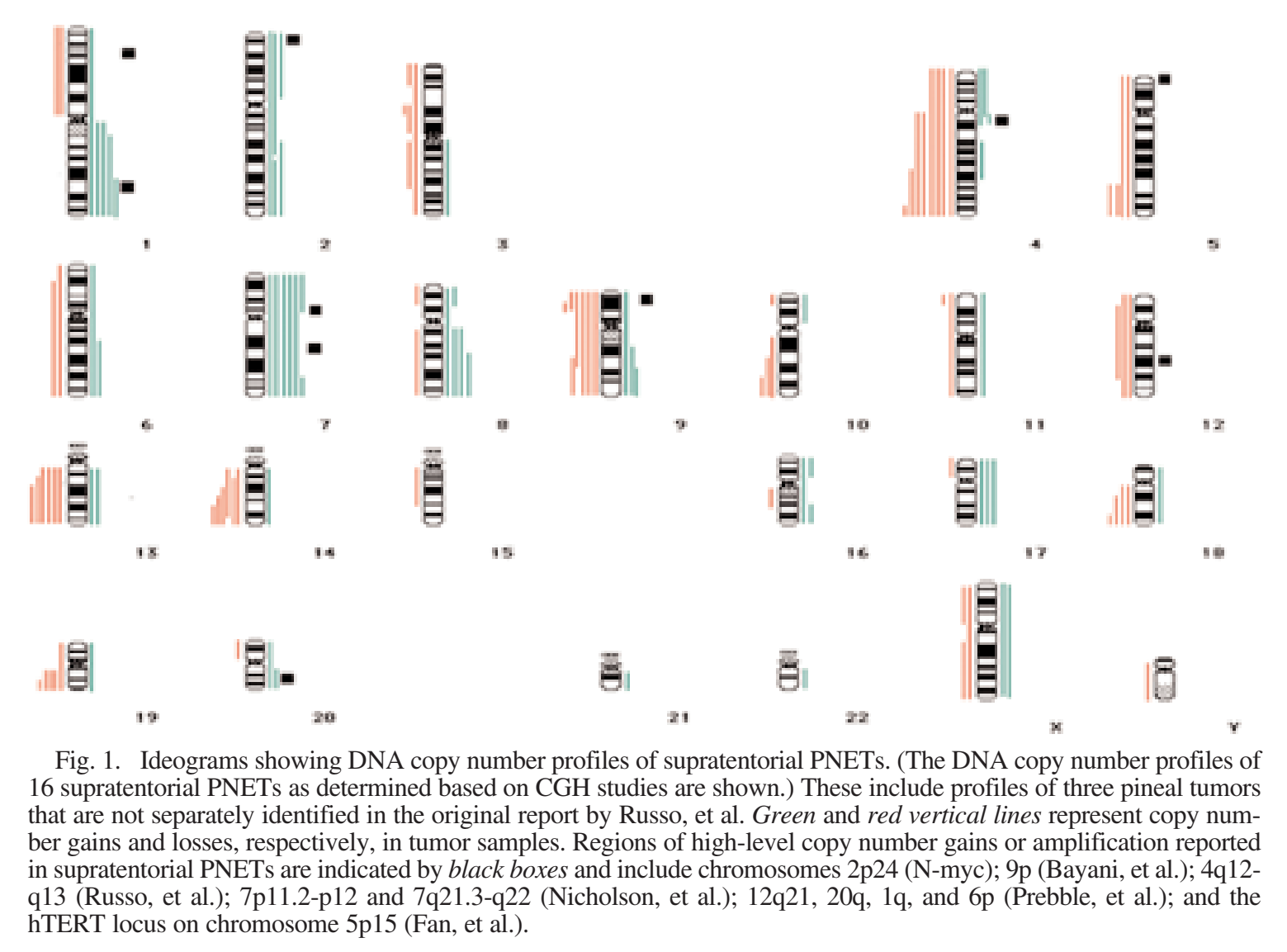

region on chromosome $17 \mathrm{p} 11.2$, which is presumed to inactivate a putative tumor suppressor in approximately $30 \%$ of medulloblastomas, is not seen in supratentorial PNETs. ${ }^{60}$

Higher frequency and greater complexity of DNA copy number changes are reported in supratentorial PNETs compared with medulloblastomas. In one of the largest studies of 17 pediatric supratentorial PNETs, in which high-resolution CGH was used, ${ }^{130}$ genomic imbalance was reported in $70 \%$ of tumors, with a median of four changes per tumor. Most changes (63\%) involved whole chromosomes, with partial chromosome imbalance seen in $37 \%$ of tumors.

Collectively, supratentorial PNETs exhibit a greater frequency of chromosome loss than gain. Distal chromosome $4 \mathrm{q}$ loss is the most frequent change, and is observed in up to $50 \%$ of the supratentorial PNETs studied.

Other regions of loss observed at significant frequency include chromosome 9 centering around distal 9p, and chromosomes 13q, and 14q. Less frequently, losses involving all or part of chromosomes 5, 6, 10q, 12,18q, and 19q are reported. Interestingly, an isolated $3 \mathrm{p} 21$ interstitial deletion has been reported in one tumor; ${ }^{115}$ it remains to be determined whether the $h M L H 1$ DNA repair gene mapping to this site is involved. Losses of chromosome $10 \mathrm{q}$ observed in approximately $25 \%$ of supratentorial PNETs appear to involve the known tumor suppressors $B T R C,{ }^{173}$ $P T E N$, or $D M B T 1$ only rarely, with only one mutation reported in $21^{81,98}$ and nine supratentorial PNETs ${ }^{81}$ for PTEN and $D M B T 1$, respectively. The $D L C-1$, a putative tumor suppressor on chromosome 8p22, is epigenetically inactivated in one of three supratentorial PNETs. ${ }^{121}$ Clearly, fur- ther studies are needed to determine the nature of putative supratentorial PNET tumor suppressor loci associated with DNA copy number losses and their mechanisms of gene inactivation in supratentorial PNETs.

Similar to observations in medulloblastomas, ${ }^{8,17}$ gains at chromosome 7 (six of 16), followed by 1q, occur most frequently in supratentorial PNETs. Gains of chromosomes 9qter, 13, and 17 have been reported in more than one case. Consistent with detection of double minutes in karyotypic studies, CGH analyses of supratentorial PNETs have identified high-level DNA amplification at chromosomes 2p24, 4q12-13, 7q21.3, and 7p11.2. Additional amplicons at chromosomes 1q;6p, 12q21, 6p, and 20q have been reported. ${ }^{130}$ With the exception of the chromosome 2p24 amplicon, which has been shown to be related to N-myc gene amplification, ${ }^{11}$ the majority of putative oncogenic loci indicated by cytogenetic findings in supratentorial PNETs remain unknown. Studies with higher-resolution single gene mapping tools (such as the recently developed array-based $\mathrm{CGH}$ technology $)^{45}$ and with larger tumor numbers will be very valuable for defining the true spectrum and frequency of genomic imbalances, and to locate oncogenes and tumor suppressor genes that underlie supratentorial PNET development.

\section{Developmental Signaling Pathways in Supratentorial PNETS}

Based on the relatively primitive histological features of these tumors, it has long been postulated that PNETs of the CNS (supratentorial PNET and medulloblastoma), arise 
from transformation of periventricular germinal matrix cells. ${ }^{159}$ Nevertheless, studies of murine models and primary human tumors have now demonstrated that some medulloblastomas can arise from germinal cells in the external granular layer of the cerebellum. ${ }^{65}$ Recently, a microarray-based study in which the expression profiles of eight supratentorial PNETs were compared with those of normal human cerebellum and medulloblastoma, showed that supratentorial PNETs have transcriptional signatures distinguishable from those of normal fetal cerebellum and medulloblastoma. In particular, medulloblastoma and supratentorial PNET differentially express cerebellar granule cell-specific transcription factors like ZIC1 and NSCL, ${ }^{127}$ supporting a cerebellar granule cell origin for medulloblastomas but not supratentorial PNETs. Although the cell of origin in supratentorial PNETs is not known, their putative derivation from cells of periventricular germinal matrix is suggested by the frequent clinical presentations of these tumors from deep periventricular locations. Histopathological studies of human pineal and midbrain tumors ${ }^{106}$ as well as studies of transgenic mice with midbrain PNET, ${ }^{107}$ also indicate that subependymal cells of the diencephalon are likely to be targets of transformation in supratentorial PNETs.

There is now overwhelming evidence that developmental signaling pathways that control normal brain development are dysregulated by tumor-specific mutations in medulloblastomas. ${ }^{156}$ Current evidence suggests that the ShhGli, Notch, and to a lesser extent Wnt (or Wingless) signaling pathways may also be involved in supratentorial PNET development.

The Shh-Gli Pathway. Extensive studies have now established a clear role for Shh signaling in normal and malignant cerebellar development. In addition, studies of human tumors and mouse models have shown that abnormal Shh signaling contributes to development of a proportion of medulloblastomas. Specifically, mutations in the $P T C H$, $S M O$, and $S U F U$ genes, leading to pathological Shh pathway activation have been demonstrated in a proportion of syndrome-associated and sporadic medulloblastomas. The Shh-Gli pathway is reviewed in detail in the article by Taylor, et al., 156 and thus only salient features are outlined here.

The role of Shh signaling in development of the cerebral cortex and the corresponding malignant tumors, such as supratentorial PNET and gliomas, has not been extensively investigated. The Ptch mutant mice, even in a p53-deficient background, have not been reported to develop supratentorial PNETs. ${ }^{169}$ Nevertheless, recent studies indicate that Shh may also serve important mitogenic functions in the developing mouse cortex. Specifically, Dahmane, et al., ${ }^{43}$ demonstrated expression of all three Gli proteins (Gli1-Gli3), which are downstream effectors of Shh signaling, in the ventricular and subventricular zone of the perinatal murine cerebral cortex and midbrain. They observed that Shh had mitogenic effects on nestin-positive neocortical precursors and cells of the ventricular zone, and could induce Gli1 in the latter cell population. These findings thus indicate that in addition to its role in cerebellar development, the ShhGli pathway may also control the development of dorsal brain/cerebral cortical growth, and contribute to the development of corresponding tumors, such as supratentorial PNET.

Due to the rarity of supratentorial PNETs, the status of the Shh-Gli signaling pathway in supratentorial PNETs remains incompletely investigated, and has generally only been reported collectively with medulloblastoma. Limited studies of supratentorial PNET tumors to date indicate however, that the Shh-Gli pathway is active, and may be altered, in a proportion of supratentorial PNETs. Specifically, expression of Gli1, Gli3, and Ptch1 transcript has been reported in one supratentorial PNET ${ }^{43}$ Increased expression of PTCH, SMO, and GLI1 mRNA has been observed in three to five of five supratentorial PNETs studied. ${ }^{136}$ In addition, all supratentorial PNET tumors in a small series of three were reported to express N-myc, a known downstream target of Shh signaling, according to immunohistochemistry studies. ${ }^{112}$ Missense mutation ${ }^{172}$ as well as loss of heterozygosity ${ }^{164}$ involving the ptch locus at chromosome $9 \mathrm{q} 22.3$ has also been reported in three of eight pediatric supratentorial PNETs studied. The functional implications of these molecular findings need to be further validated in appropriate tumor models. Nonetheless, these limited studies indicate that Shh-Gli1 pathway aberrations are likely to have a pathogenetic role in at least a proportion of supratentorial PNETs. The scope of Shh-Gli1 pathway involvement in supratentorial PNET, and whether they correlate with any specific histopathological features in these tumors must await studies conducted in larger numbers of tumors.

Notch-Hes Signaling. Experimental evidence from murine studies indicates that the Notch signaling pathway plays an important role in regulating normal neurogenesis by restricting neuronal differentiation and promoting maintenance of progenitor cells. ${ }^{83}$ Notch family genes encode large transmembrane proteins (Notch 1-4) with extracellular endothelial growth factor-like repeats that act as receptors for membrane-bound ligands (Jagged, delta) expressed by neighboring cells (Fig. 2). Current evidence supports the proposition that Notch signaling may act negatively or positively to regulate cellular proliferation or differentiation depending on the cell context. Notch signaling is activated by ligand binding and involves complex cleavage and release of an intracellular Notch fragment (the Notch intracellular domain), which translocates to the nucleus. The Notch intracellular domain heterodimerizes with the DNA binding transcription factor CBF1 to activate target genes of the Hes (1-5) family. The best-characterized Notch effector, Hes 1, negatively regulates basic helix-loop-helix neurogenic transcription activators such as hASH1. ${ }^{38,153}$ The Hes 1 is highly expressed in the ventricular zone of the developing nervous system, and misexpression of Hes 1 has been shown to prevent neural differentiation. ${ }^{83,117}$

Aberrant Notch signaling has been linked to a spectrum of human malignancies including T-cell leukemia, in which a $\mathrm{t}(7: 9)$ translocation results in a constitutively active and oncogenic Notch 1 molecule (see review by Allenspach, et al. ${ }^{5}$. Investigations of Notch signaling in PNETs and medulloblastomas of the CNS are at an early stage, with only a few studies reported to date. These studies, however, demonstrate evidence of Notch pathway activation in PNETs of the CNS, and differential expression of Notch pathway components in medulloblastoma and supratentorial PNETs, perhaps reflecting distinct cells of origin for these tumors. In one study of 13 medulloblastomas and five supratentorial PNETs, hASH1 expression was seen in three of five 


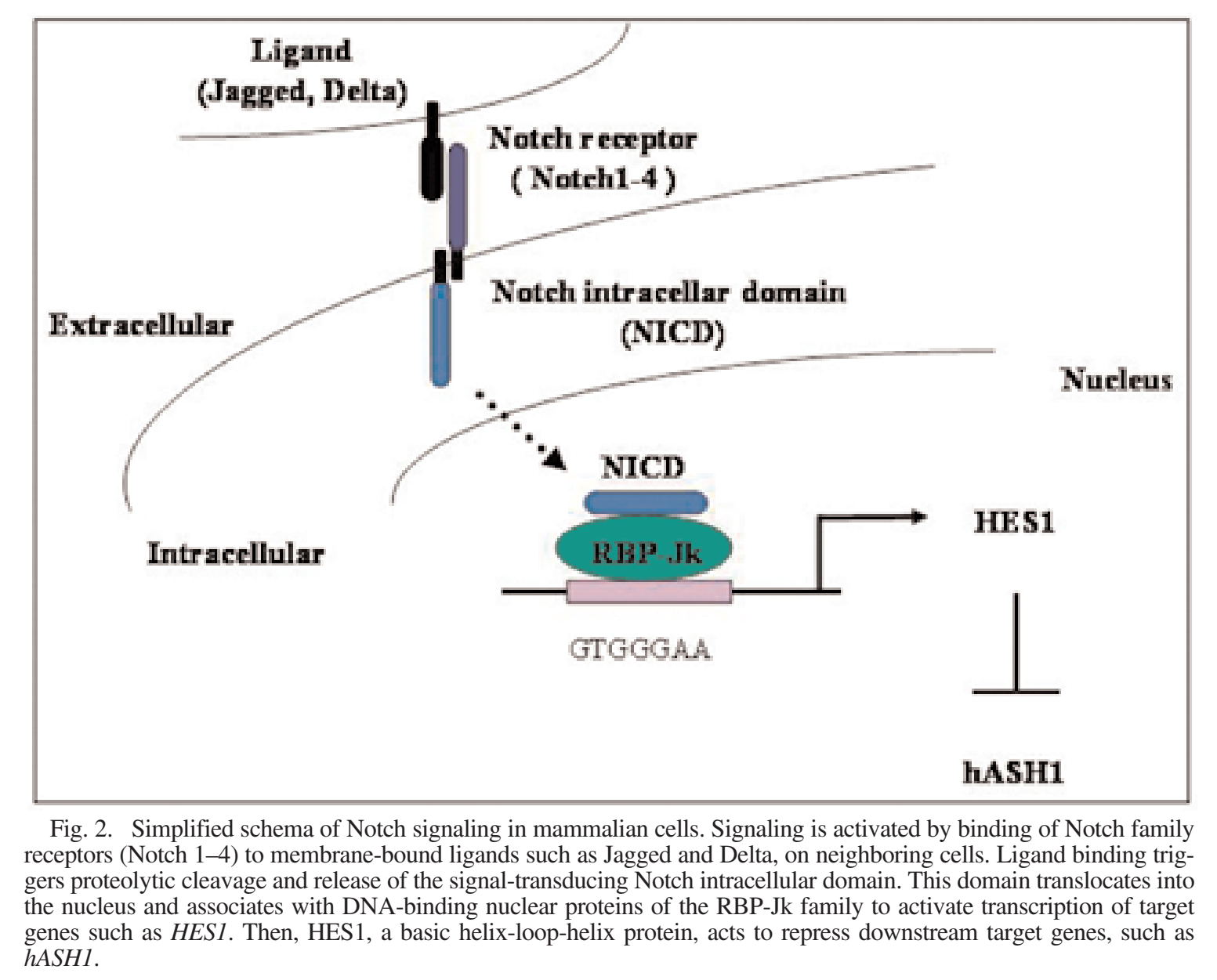

supratentorial PNETs and none of 12 medulloblastomas, whereas expression of NeuroD genes appeared to be more prevalent in medulloblastomas. ${ }^{143}$

A more recent study ${ }^{54}$ has shown differential expression of Notch 1 and Notch 2 in supratentorial PNETs compared with medulloblastomas, with a greater prevalence of high Notch 2 expression in supratentorial PNETs. Indeed, more than $50 \%$ of supratentorial PNETs, including a supratentorial PNET cell line, expressed extremely high levels of Notch 2 mRNA, whereas both primary medulloblastomas and two cell lines expressed Notch 2 and Notch 1 at levels comparable to control cerebellar cells. Significantly, three of six tumors with high Notch 2 mRNA had genomic amplification or copy number gains of the Notch 2 locus on chromosome 1p11-13, and Notch 2 knockdown in PFSK, a supratentorial PNET cell line, ${ }^{62}$ resulted in inhibition of cell growth, thus supporting a functional role for Notch 2 in supratentorial PNET. Interestingly, a second study has reported more frequent Notch 1 than Notch 2 overexpression in medulloblastoma, and demonstrates HES1 and/or HES5 as Notch effectors in medulloblastoma. Whether these two tumor types can indeed be differentiated by their Notch activation profile remains to be confirmed in studies with a larger number of cases. Further studies will also be necessary to determine the prevalence of Notch 2 dysregulation by gene amplification, or alternate mechanisms in supratentorial PNETs. Intriguingly, recent studies of transgenic medulloblastoma mice with targeted overexpression of the Shh pathway gene (Smo) to the cerebellar external granule layer through a NeuroD2 promoter ${ }^{70}$ suggest crosstalk between Notch and Shh signaling in medulloblastoma. Whether the same will hold true in supratentorial PNET remains to be seen.

The Wnt Pathway. The Wnt (or Wingless) pathway is a highly conserved signaling pathway with a key role in control of cellular proliferation, differentiation, migration, and adhesion. A role for Wnt signaling in brain tumor development was first recognized through studies of Turcot syndrome, a heritable association of CNS neuroepithelial tumors and adenomatous polyposis of the large intestine caused by germ line mutations of the APC gene. ${ }^{71}$

The APC protein normally exists as part of a large degradative protein complex that includes Axin, GSK-3 $\beta$, and $\beta$-catenin. This protein tightly regulates the subcellular location and function of $\beta$-catenin, a key transcriptional effector of Wnt signaling. ${ }^{90}$ In the context of appropriate growth or differentiation signals, Wnt signaling is activated by ligand binding to Frizzled transmembrane receptors, which triggers degradation of GSK $3 \beta$ and consequently inactivates the APC complex. In the absence of degradative signals, accumulated cytosolic $\beta$-catenin translocates to the nucleus, and acts with TCF transcription factors to activate target genes, which include the c-myc oncogene. ${ }^{73}$ The $\beta$ catenin also acts to regulate cell adhesion by associating 
with membrane-bound cadherin proteins. Tumor-specific mutations of Wnt pathway components have been described in medulloblastomas, in which c-myc and $\mathrm{N}-m y c$ activation are reported in a substantial proportion of tumors. ${ }^{4,52}$

The Wnt pathway aberrations have not been extensively investigated in supratentorial PNETs. Single $\beta$-catenin mutation was reported in a small study of four supratentorial PNETs. ${ }^{95}$ This mutation, which resulted in a somatic Gly to Val change within a protein degradation targeting signal in exon 3, correlated with $\beta$-catenin nuclear accumulation and Wnt activation. Increased expression of c-myc and N-Myc, a downstream $\beta$-catenin target, has been reported in supratentorial PNET cell lines ${ }^{90}$ suggesting potential etiological roles for the Wnt pathway in supratentorial PNET development. Nevertheless, further studies are needed to assess the prevalence of Wnt pathway aberrations in supratentorial PNET.

\section{Tumor Suppressor Loci in Supratentorial PNETs}

Genomic mapping studies indicate a putative supratentorial PNET suppressor loci on chromosomes 4q, 9p, 13, and $14 q$, in which DNA copy number losses are most often observed. ${ }^{115,130,146}$ The identities of these putative loci remain to be determined. Known tumor suppressor pathways with evidence of involvement in supratentorial PNET development are discussed later.

The p53 Locus. The p53 tumor suppressor locus on chromosome $17 \mathrm{p} 13.1$ is one of the most frequently mutated genes in human cancers. Nullizygous p53 mice are viable but highly susceptible to tumor development. ${ }^{49}$ In humans, germ-line p53 mutations result in the Li-Fraumeni syndrome, a rare heritable cancer syndrome associated with diverse malignancies, including brain tumors. ${ }^{105} \mathrm{~A}$ key cellular function of p53 (extensively reviewed in Bourdon, et al. ${ }^{26}$ ) is to inhibit malignant cell transformation resulting from events such as DNA damage or ectopic oncogene expression, by induction of genes involved in cell cycle arrest and apoptosis. Most p53 mutations in human cancers result in structural alterations with loss of wild-type p53 growth inhibitory functions and may also generate mutant p53 proteins with dominant negative properties or gain of new biochemical and biological functions that promote malignant cell growth. ${ }^{24}$ Due to its central role in controlling cell growth, p53 function is normally tightly regulated by a variety of cellular mechanisms that may also be targeted in tumor cells. ${ }^{163}$ These include amplification of the MDM2 oncogene on chromosome 12q14, a ubiquitin ligase that facilitates proteosomal degradation of p53. Loss of p15ARF, a critical upstream activator of $\mathrm{p} 53,{ }^{151}$ can also represent a common mechanism of functional p53 loss in tumors (described in the following section).

Supratentorial PNET as well as medulloblastoma have been described in familial Li-Fraumeni syndrome, ${ }^{166}$ but because PNETs of the CNS were described collective$1 y,{ }^{48,56,119}$ the specific incidence of either tumor type in LiFraumeni syndrome is not known. Germ line p53 mutations described in supratentorial PNETs involve codon 213, and an unusual CAT to AAT transversion in codon 179, ${ }^{129}$ suggesting the possibility of other atypical p53 mutations in supratentorial PNET.

Although p53 mutations are estimated to occur in ap- proximately $27 \%$ of all brain tumors, ${ }^{118}$ these mutations occur rarely $(<1 \%)$ in sporadic malignant pediatric brain tumors. ${ }^{128}$ The relative lack of $p 53$ mutations in pediatric brain tumors have been corroborated by individual studies of pediatric supratentorial PNETs. Mutational studies of a sum of 28 pediatric supratentorial PNETs in four separate studies $^{30,74,98,99,133}$ have identified only one somatic $p 53 \mathrm{mu}-$ tation. ${ }^{98}$ Interestingly, in a study of 14 adult and pediatric cerebral PNETs, $p 53$ mutations were observed in six of 11 cases in adults and none of three pediatric supratentorial PNETs. ${ }^{74}$ These observations lead us to suggest that, similarly to pediatric high-grade gliomas, ${ }^{138}$ childhood supratentorial PNETs may differ genetically from the corresponding tumors in adults.

Despite the rarity of $p 53$ mutations in sporadic supratentorial PNET, a role for this gene in supratentorial PNET pathogenesis is suggested by development of supratentorial PNET in several p53-/- murine brain tumor models, ${ }^{158,177}$ and in SV40 T antigen-driven transgenic PNET models. ${ }^{2,107}$ In addition, high p53 protein expression, indicative of p53 dysfunction, is seen in a significant proportion of supratentorial PNETs. ${ }^{31,51,87,174}$ The true frequency of p53 immunopositivity in supratentorial PNETs is not known because studies have often considered medulloblastoma and supratentorial PNET collectively. Nevertheless, studies of 12 cases of supratentorial PNET in two small series (one included three medulloepitheliomas) suggested that up to 90\% of supratentorial PNETs display p53 dysfunction, as indicated by strong p53 positivity. ${ }^{51,87}$ In contrast, strong p53 immunopositivity is reported in 10 to $30 \%$ of medulloblastomas. ${ }^{51,134}$ Correlation of $p 53$ mutations was not conducted in these studies; thus the mechanisms for p53 immunopositivity in these tumors are not known. Studies conducted in a small number of tumors indicate that $\mathrm{mdm} 2$ amplification may not be a common mechanism for p53 loss in supratentorial PNETs. Mutually exclusive mutations in p53, methylation of p14 ${ }^{\mathrm{ARF}}$, or deletion of INK4/ARF, have recently been demonstrated in up to $25 \%$ of medulloblastomas. ${ }^{58}$ Thus, a greater role for $\mathrm{p} 53$ and $\mathrm{p} 53$ regulatory pathways in supratentorial PNET development may yet be demonstrated.

Recently, several novel members of the $\mathrm{p} 53$ protein family (p63 and p73) that have roles in oncogenesis have been identified. ${ }^{82}$ In addition, p53 isoforms resulting from alternative splicing have also been reported. ${ }^{25}$ The significance of these novel p53 family members/isoforms in supratentorial PNET development remains to be investigated.

The INK4/ARF Pathway. The cdk/INK4/pRB pathway is a key mediator of mitogenic and antimitogenic signals necessary for normal cellular proliferation. Not surprisingly, this pathway is deregulated in more than $80 \%$ of human tumors by genetic and epigenetic alterations of different components, as reviewed in various studies (Fig. 3). ${ }^{120,144,151}$

The INK4a/ARF locus on chromosome 9p21 encodes two distinct tumor suppressor proteins (p16INK4a and p15ARF), which normally act in parallel to regulate the function of the $\mathrm{pRB}$ and $\mathrm{p} 53$ tumor suppressors, respectively. In normal cells, wild-type P16INK4a maintains the pRB tumor suppressing function by inhibition of cdk4 and cdk6 activity, resulting in pRB hypophosphorylation, E2F repression, and induction of $\mathrm{G}_{1}$ arrest. In tumor cells, deletions or mutations of p16INK4a renders it ineffective for regulation of cdk $4 / 6$ activity, resulting in $\mathrm{pRB}$ hyperphos- 
phorylation, loss of $\mathrm{E} 2 \mathrm{~F}$ repression, and activation of genes permissive for $\mathrm{G}_{1}-\mathrm{S}$ phase transitions and unregulated cellular proliferation. Under normal cellular growth conditions, p15ARF acts to stabilize p53 by binding to MDM2. Loss of P15ARF function through genetic and epigenetic mechanisms in tumor cells results in functional loss of p53, as reviewed in Roussel ${ }^{144}$ and Sherr. ${ }^{151}$

The INK4 proteins (a-d) are highly conserved and have partly redundant functions that remain incompletely elucidated. Like INK4a and b, the INK4c and d proteins regulate $\mathrm{pRB}$ function by specifically inhibiting cdk4 and cdk6 activity. ${ }^{68}$ Unlike P15INK4b and P16INK4a, however, the $\mathrm{P} 18 \mathrm{INK} 4 \mathrm{c}$ and/or P19INK4d show temporal and spatial expression in the developing and mature brain, leading to the suggestion that these proteins may have context-specific tumor suppressor functions. Loss of Ink $4 \mathrm{c} / \mathrm{d}$ or $\mathrm{p} 53^{49}$ alone do not predispose mice to brain tumors. Nevertheless, Zindy, et al. ${ }^{177}$ described a spectrum of tumors, including brain tumors in p53 null mice with homozygous loss of Ink4c or Ink4d. Mice with homozygous or heterozygous loss of Ink4c developed cerebellar tumors resembling medulloblastoma. Interestingly, mice with only Ink4d loss developed cerebral tumors resembling human supratentorial PNET. In addition to cerebellar tumors, mice heterozygous for Ink4d and Ink4c developed supratentorial PNET-like tumors originating from periventricular zones and thalamic locations. It is noteworthy that Ink4d is normally expressed in the progenitor cells of the rat telencephalon and neonatal subventricular zone, ${ }^{42}$ and that it has been implicated in inhibition of postnatal neuronal differentiation. ${ }^{176}$ These observations indicate cooperative tumorigenic effects of p53 and the INK4c and INK4d proteins, and perhaps a more specific requirement for INK4d inactivation in supratentorial PNET development.

As described in the preceding section, there is evidence of p53 dysfunction in a substantial proportion of supraten-

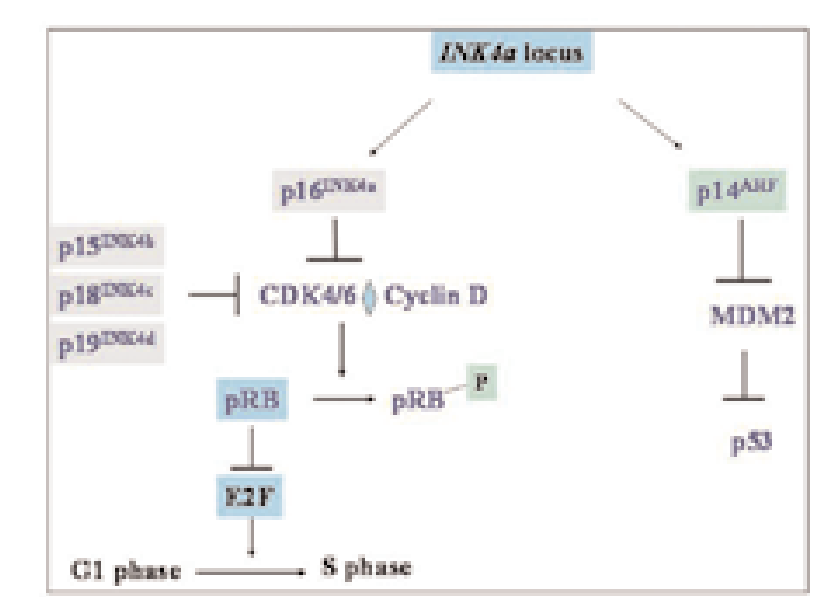

Fig. 3. Chart showing regulation of $\mathrm{pRB}$ and $\mathrm{p} 53$ by the INK4a/ARF tumor suppressor pathway. A simplified schema of the INK4a/pRB/p53 pathway is shown. The INK4a locus encodes $\mathrm{p} 16^{\mathrm{INK} 4 \mathrm{a}}$ and ARF through the use of alternate reading frames. The p16 ${ }^{\text {INK4a }}$ and related INK4 proteins (INK4b-d) inhibit cdk4/6 activity with consequent hypophosphorylation of pRB. Hypophosphorylated $\mathrm{pRB}$ acts with E2F proteins to repress transcription of genes necessary for the $\mathrm{G}_{1}-\mathrm{S}$ phase transition. The P14 ${ }^{\mathrm{ARF}}$ regulates p53 activity by inhibiting MDM2-mediated degradation of $\mathrm{p} 53$, allowing p53 to induce cell cycle arrest. torial PNETs studied to date. The status of the INK4/ARF and cdk4/6 loci has not been specifically investigated in supratentorial PNET. It is significant that although only rare p16 deletions in medulloblastoma had been identified in previous studies, ${ }^{10,124,144,147}$ more recent reports demonstrate that up to $25 \%$ of the large cell aggressive variant of medulloblastoma show evidence of genetic or epigenetic lesions in the INK4/ARF/p53 pathway. ${ }^{58}$ It is interesting that in the study by Zindy, et al., ${ }^{177}$ mice heterozygous for both Ink $4 \mathrm{c}$ and Ink4d developed both medulloblastoma and midline supratentorial PNET-like tumors, thus raising the possibility that a spectrum of medulloblastoma, such as the anaplastic variant, may share etiological pathways with supratentorial PNETs.

The PMS2 Pathway. Both medulloblastoma and supratentorial PNET have been linked to Turcot syndrome, which is characterized by concurrence of primary brain tumor and multiple colorectal adenomas. Two types of syndromes are recognized: Turcot Type 2 occurs in the setting of familial adenomatous polyposis and involves germ line mutations of the APC gene on chromosome $5 \mathrm{q} 21 .{ }^{71}$ The predominant brain tumor in Turcot Type 2 is medulloblastoma, in which syndrome-associated mutations in APC or beta-catenin mutations have been demonstrated. ${ }^{78,156,178}$

Turcot Type 1 comprises a second syndrome with clinical findings of nonfamilial adenomatous polyposis-associated colorectal cancer (hereditary nonpolyposis colorectal cancer), skin lesions (including café-au-lait spots-), and glioblastoma. It is a genetically heterogeneous disease resulting from germ-line defects in several DNA mismatch repair genes, including $h M L H 1$ (3p21 locus), $h M S H 2$ (2p16), hMSH3 (5q11-q13), hMSH6 (2p16), hPMS1 (2q31), and $h P M S 2$ (7p22). Defects in these loci lead to genetic instability in which short repeated sequences (microsatellites) are characteristically altered due to accumulation of unrepaired somatic mutations. ${ }^{71}$ The PMS2 and hMLH1 gene products form heterodimers and provide one of the major DNA mismatch repair activities in mammalian cells. Although MLH1 mutations are commonly seen in hereditary nonpolyposis colorectal cancer, germ-line mutations of PMS2 have been described only recently. ${ }^{46,114,148}$ DeVos, et al., reported on two siblings with supratentorial PNETs in a heavily consanguineous family with cosegregation of learning difficulties, cutaneous café-au-lait spots, and early-onset brain tumors inherited in a recessive fashion. A homozygous missense mutation in exon 14 of PMS2 leading to protein truncation was demonstrated in all affected individuals.

In addition to the detection of germ line PMS2 mutations in supratentorial PNETs, several other observations indicate that signaling pathways involved in DNA damage repair are important in supratentorial PNET development. These include, as described earlier, high-level expression of p53 protein in a large proportion of supratentorial PNETs and development of supratentorial PNET radiation-induced secondary malignancies as well as rare supratentorial PNETs in the setting of multiple sequential malignancies. ${ }^{135} \mathrm{In}$ addition, we have observed unusual karyotypes indicative of an underlying DNA breakage syndrome in a case of sporadic supratentorial PNET (Fig. 4; L Lafay-Cousin and A Huang, unpublished data). Furthermore, supratentorial PNETs have been reported in two different medulloblastoma mouse models with disruptions of genes that have im- 
portant functions in DNA repair, such as $p 53^{177}$ or PARP-1 (a DNA damage response gene). ${ }^{158}$

The status of the other DNA mismatch repair genes and of PARP-1 in sporadic supratentorial PNET remains to be investigated. It is interesting to note that overlapping losses centering around chromosome 3 p21 have been reported in CGH studies of supratentorial PNETs, ${ }^{115}$ thus suggesting potential for hMLH1 loss in a proportion of supratentorial PNETs.

The prevalence of PMS2 mutations in hereditary and sporadic supratentorial PNET is also not known, and may prove challenging to determine because multiple PMS2 pseudogenes are located on chromosome 7. Recent studies $^{46,114}$ demonstrate that these pseudogenes on chromosomes 7q13-q12, 7q11, and 7q22 can obscure detection and lead to underdiagnosis of PMS2 mutations. Use of a recently developed PMS2 antibody may help identify patients with putative PMS2 mutations for comprehensive mapping studies in supratentorial PNET.

The hSNF5/INII Pathway. Central nervous system atypical rhabdoid teratoid tumors are aggressive lesions that have overlapping clinical, histological, and radiographic features with medulloblastoma or PNET. ${ }^{141}$ In particular, the clinical diagnosis and differentiation of supratentorial PNETs from atypical rhabdoid teratoid tumors in a young child have posed significant challenges in the past because both tumors can show predominantly undifferentiated histological features with focal areas of divergent differentiation. ${ }^{99}$ A tumor suppressor (hSNF5/INI1) mapping to chromosome 22 has now been identified for atypical rhabdoid teratoid tumors. The hSNF5/1N1 gene product is a component of the SW1/SNF chromatin remodeling complex. ${ }^{80}$ Nonrandom association of monosomy on chromosome 22 that typically characterizes atypical rhabdoid teratoid tumors has also been reported for histologically confirmed

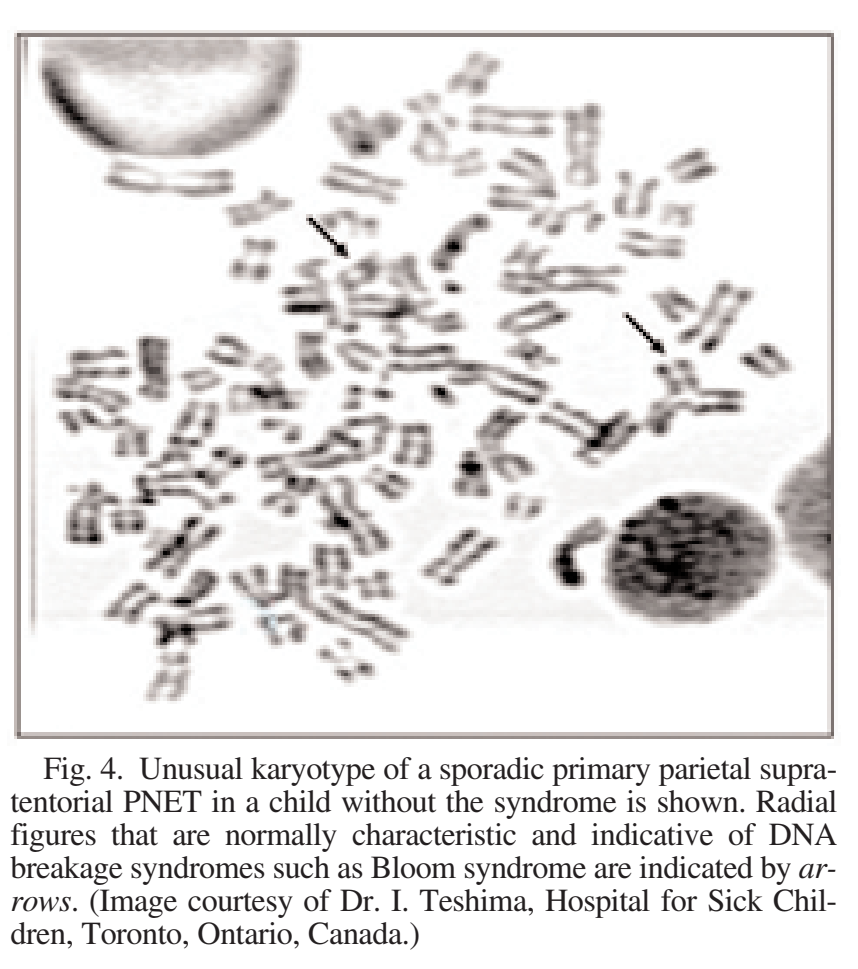

medulloblastoma and, less frequently, in supratentorial PNET. Studies of INI in medulloblastoma and supratentorial PNET have revealed only very few INI1 mutations, ${ }^{18,99}$ indicating that a distinct chromosome 22 tumor suppressor gene is involved in medulloblastoma and/or supratentorial PNET development. Nonsense mutations resulting in a truncated INI1 gene product were reported in two of 17 supratentorial PNETs in an investigation of hSNF5/INI1 alterations in 229 tumors of various origins. ${ }^{149,150} \mathrm{Germ}$-line INI1 mutations have been reported in rare families with choroid plexus carcinomas, central PNETs, or medulloblastomas presenting in very young children. In addition, de novo constitutional INI1 mutation associated with a supratentorial PNET and a renal rhabdoid tumor has been described. ${ }^{149,150}$

\section{Molecular Correlates of Disease Phenotypes in Supratentorial PNET}

Prognostic roles for erbb2, myc, p53, and Trk receptor expression have been demonstrated in medulloblastoma. The status of erbb2 in supratentorial PNET is not known. Apart from p53, the other markers have only been examined in a handful of supratentorial PNETs ${ }^{67,116}$ collectively with medulloblastoma. Because only very few tumors have been studied with individual markers, their correlation, if any, with clinical phenotypes in supratentorial PNETs cannot be determined based on the current data. It is interesting to note, however, that in studies in which supratentorial PNETs and medulloblastomas have been collectively analyzed for individual markers such as p53 immunopositivity, ${ }^{51}$ Notch $2,{ }^{54}$ or hTERT ${ }^{55}$ gene activation, the supratentorial PNETs tend to segregate with more aggressive medulloblastoma variants. It will clearly be of interest to determine whether aggressive variants of medulloblastoma share additional overlapping molecular features with supratentorial PNETs.

\section{PINEOBLASTOMAS}

Pineoblastomas make up 45 to $50 \%$ of pineal parenchymal tumors, and are classified as WHO Grade IV tumors with typical variable reactivity to neuronal and glial markers. ${ }^{110}$ Like cerebral supratentorial PNET, pineoblastoma is mainly a childhood disease, with cases only occasionally described in adults..$^{91,111}$ Due to their poorly differentiated histopathological features, they have generally been studied together with other undifferentiated embryonal intracranial PNETs. They have been collectively analyzed with cerebral PNETs in most therapeutic and molecular studies, comprising 20 to $50 \%$ of reported supratentorial PNETs in such series. . $^{40,47,108,123,135,157}$ Nevertheless, there is some suggestion that in very young children ( $<18$ months), pineal tumors may occur at a higher frequency than nonpineal lesions. ${ }^{63}$ Indeed, tabulation of published cytogenetic data indicates that 40 to $50 \%$ of pineoblastomas occur in children less than 1 year old (Table 2).

It is noteworthy that pineoblastomas may exhibit histopathological features indicative of photosensory differentiation ranging from focal expression of retinal S-antigen to characteristic Flexner-Wintersteiner rosettes and fleurettes reminiscent of retinoblastic differentiation (Fig. 5). ${ }^{9,110} \mathrm{Em}-$ bryologically, the pineal gland develops from primitive 
neuroepithelial cells, which line the diencephalic $\operatorname{roof}^{145}$ and have features of photoreceptor organs, with photosensory and neuroendocrine differentiation. These cells are believed to be ontogenetically linked to the photoreceptor cells of the retina. The histological features of pineal and suprasellar PNETs arising in the context of trilateral retinoblastoma (described later), can bear exceptionally close resemblance to retinoblastoma, and this tumor type has been labeled by some as "primary ectopic intracranial retinoblastoma.", 92 Thus, at least a proportion of pineoblastomas may share ontogenic aspects with precursor cells targeted for transformation during retinoblastoma development.

\section{Heritable Pineoblastoma}

Tumors presumed to be heritable nonsyndromic pineoblastomas have unknown molecular sources and have been described only rarely. These include cases of pineoblastoma in a mother and a daughter, ${ }^{101}$ sequential development of pineoblastoma and pilocytic astrocytoma in one individual, ${ }^{29}$ and identical twins with discordant presentation of PNET; one with pineoblastoma and the other with a medulloblastoma. ${ }^{165} \mathrm{~A}$ rare association of pineoblastoma with familial adenomatous polyposis has also been reported. ${ }^{79}$

Significantly, pineoblastoma can present in the setting of heritable and sporadic retinoblastoma. Trilateral retinoblastoma, a condition first described in $1971{ }^{88}$ is characterized by an intracranial neuroblastic tumor that typically occurs in the setting of germ-line $R B 1$ gene mutations and heritable disease that manifests as bi- or multifocal disease or family history. Less frequently, trilateral retinoblastoma can manifest with unilateral ocular retinoblastoma. ${ }^{170}$ Rare germ-line mutations of $R B$ manifest as "forme fruste" $\mathrm{Rb}$, with only intracranial PNET, and no ocular tumors. ${ }^{122} \mathrm{Up}$ to $6 \%$ of patients with bilateral retinoblastoma and $10 \%$ of patients with a family history of these lesions have been reported to harbor an intracranial PNET in one study. ${ }^{22}$ Trilateral retinoblastoma develops within a median duration of 21 to 23 months from the retinoblastoma diagnosis, has a dismal prognosis, and a 6 month median survival duration following diagnosis of the intracranial tumor. ${ }^{92,122}$ The bleak outlook warrants measures for reductive therapy and early screening in hereditary retinoblastoma.

Trilateral retinoblastomas with intracranial disease that precede the development of retinoblastoma have been exceptional. ${ }^{9,57}$ More than $80 \%$ of PNETs associated with retinoblastomas are pineal in location, whereas supra- or parasellar tumors comprise less than $20 \%$ of intracranial tumors in trilateral retinoblastoma. Rare cases of this disease with cerebellar/fourth ventricular PNET/medulloblastoma have been reported. ${ }^{53,57}$ Nevertheless, we are aware of only one case of cerebral PNET reported in association with retinoblastoma. Dorfmuller, et al., ${ }^{50}$ described a child in whom a temporal-parietal supratentorial PNET developed 5 years after radiation therapy for a unilateral retinoblastoma. Nevertheless, the atypical location and exceptionally long lag time to development of the intracranial lesions suggests a therapy-related secondary tumor rather than a manifestation of trilateral retinoblastoma.

The observed differences in histological features and location of trilateral retinoblastoma-associated PNET suggest that pineal/suprasellar PNETs and nonpineal cerebral supratentorial PNETs may arise from distinct precursor cell populations. In this respect, it may be relevant that pineal PNETs presenting in very young children are reported to have worse outcomes than cerebral supratentorial PNETs. ${ }^{63,157}$ Curiously, several therapeutic studies have reported opposite trends in older children, with superior survival rates and lower incidences of metastatic disease in pineal compared with nonpineal supratentorial PNETs. ${ }^{40,47,86}$ Whether these observed differences reflect true age-related differences in tumor biology or result from earlier clinical manifestations and hence detection of pineal region tumors is not known.

\section{The RB1 Locus}

The gene of origin for retinoblastoma on chromosome $13 \mathrm{q} 14$ (RB1) was one of the first tumor suppressors identified through studies of heritable cancer syndromes..$^{59,100}$ The pRB pathway has been expertly discussed in several reviews, ${ }^{72,154,167}$ and only its salient features are detailed here and illustrated in Fig. 6.

The RB1 gene product is a nuclear protein that is expressed in many cell types. In addition to a critical role in cell cycle regulation, $\mathrm{pRB}$ is also implicated in cellular differentiation, senescence, apoptosis, and embryonic development. One of the best-characterized and critical functions

TABLE 2

Literature review and summary of published karyotypes for pineoblastomas*

\begin{tabular}{|c|c|c|c|c|}
\hline Authors \& Year & $\begin{array}{l}\text { Tumor } \\
\text { No. }\end{array}$ & $\begin{array}{l}\text { Patient Age, } \\
\text { Sex }\end{array}$ & Comment & Karyotype \\
\hline \multirow[t]{2}{*}{ Griffin, et al., 1988} & 3 & 3 yrs, F & trilat retinoblastoma & 42:46;XX,del(1)(p13-21) der(1)t(1;?)(p36) \\
\hline & 4 & $10 \operatorname{mos}, \mathrm{M}$ & trilat retinoblastoma & 45-47;XY,der(1)t(1;?)(q44) \\
\hline Sreekantaiah, et al., 1989 & 8 & $2.5 \operatorname{mos}, \mathrm{M}$ & primary & $46, \operatorname{del}(11)(\mathrm{q} 13.1 \mathrm{q} 13.5)$ \\
\hline Kees, et al., 1994 & 9 & 8 mos, NR & cell line PER-452 & iso $17 \mathrm{q} \dagger$ \\
\hline Agamanolis \& Malone, 1995 & 2 & 10 yrs, F & primary & $46, \mathrm{XX}$ \\
\hline Bigner, et al., 1997 & 1 & $1.5 \mathrm{yrs}, \mathrm{F}$ & primary & $46, \mathrm{XX},+14,-22 / 46$, idem; $-20,+\operatorname{mar}^{3}$ \\
\hline Kees, et al., 1998 & 10 & 11 mos, NR & cell line PER-480 & $46, X Y, \operatorname{der}(10) \mathrm{t}(10 ; 17)(\mathrm{q} 21 ; \mathrm{q} 22-23), \operatorname{der}(16) \mathrm{t}(1 ; 16)(\mathrm{q} 12 ; \mathrm{q} 11.2) \neq$ \\
\hline \multirow[t]{2}{*}{ Roberts, et al., 2001} & 5 & NR & primary & $46, \mathrm{XX},-22$ \\
\hline & 6 & NR & primary & $\begin{array}{l}63-82, \mathrm{XXX} ;+2,-3,+4,+5,+7,+9,+11,+12,-14,+15,+16,+17,+18,+20 \\
\quad+21,+22(\mathrm{cp} 6)\end{array}$ \\
\hline Batanian, et al., 2003 & 7 & $8 \mathrm{mos}, \mathrm{F}$ & & 50,XX,YYY,+9; +13, +1q; +19p: 17; complex t(1:11;18) \\
\hline
\end{tabular}

$* \mathrm{NR}=$ not reported.

$\dagger \mathrm{N}$-myc protein overexpression reported.

$\$ c$-myc protein overexpression reported. 


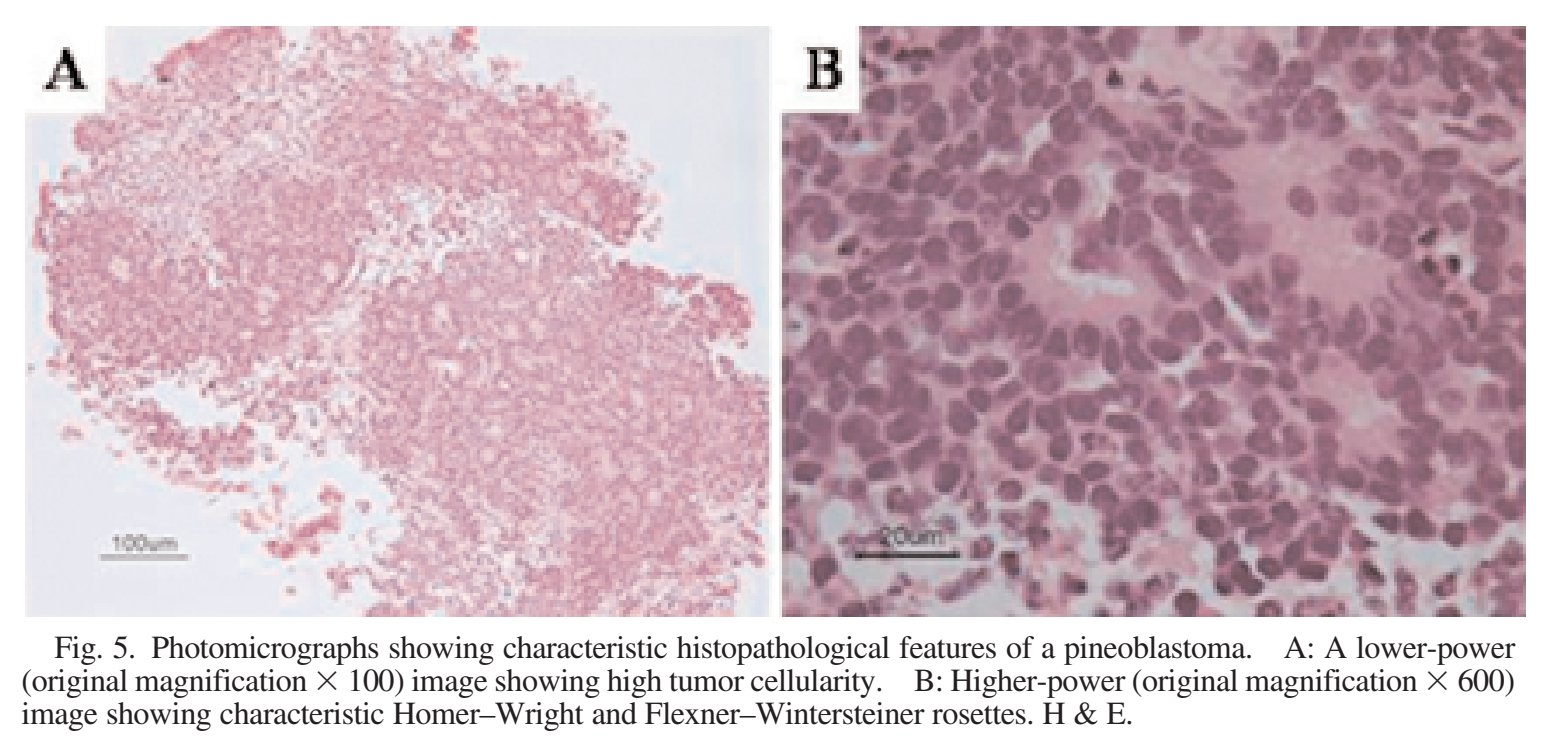

of the $\mathrm{pRB}$ protein is that of a transcriptional repressor, a function that is mediated through interactions with different E2F (E2F1-5) protein family members. The E2F proteins normally activate gene transcription by binding to consensus positive regulatory DNA elements in gene promoters. The E2F:RB interactions are tightly controlled by the oncogenic cell cycle-specific proteins; cyclins D1 through D3, cyclin $\mathrm{E}$, and their associated cdks (cdk2/4/6). ${ }^{154}$ In quiescent cells, hypophoshorylated $\mathrm{pRb}$ exists in a complex with E2F4 and other proteins, including p130 and DP1, and acts to recruit chromatin-remodeling proteins such as histone deacetylase $\mathrm{e}^{27,103,104}$ to effect "closed chromatin conformation" and consequent gene repression. When normal cells are stimulated with mitogens, hyperphosphorylated $\mathrm{pRB}$ generated by increased activity of cyclin:cdk $4 / 6$ complexes dissociates from E2F proteins, and enables "switching on" of gene transcription mediated through E2F-binding DNA elements. ${ }^{168}$ The silencing of genes needed for cells to enter the $\mathrm{G}_{1}-\mathrm{S}$ phase of the cell cycle is believed to be one of the critical cellular functions of $\mathrm{pRB}$, which is abrogated in cells with genetic or functional loss of this protein.

Structurally, pRB belongs to a family of so-called pocket proteins (other members are the p107 and p130 proteins), characterized by a small "pocket domain" critical for interactions with a variety of cellular proteins, including Dcyclins, associated cdk6, and HDAC1 (a histone deacetylase molecule involved in transcriptional repression by pRB). These proteins share a short conserved LXCXE peptide motif that binds the small pocket domain in $\mathrm{pRB}$ and other pRB-related proteins. ${ }^{152}$ Significantly, similar motifs are found in oncogenic DNA tumor viruses such as E1A, SV40 large T, and the HPV E7 antigens, ${ }^{77,125}$ which are known to target $\mathrm{pRB}$ through the pocket domain during cellular transformation. These observations underscore the importance of $\mathrm{pRB}$ transcriptional repressor functions in maintaining normal cellular phenotypes.

\section{Pineoblastoma in Rb Knock-Out Mice}

The RB1 gene product has a central function in cell growth regulation, and is ubiquitously expressed in many cell types and tissues. The reason for the narrow spectrum of human cancers seen with germ-line RB1 mutations remains unknown, but is proposed to be related to the intrinsic death resistance phenotypes of retinoblastoma precursor cells. $^{28,36}$ Surprisingly, several $\mathrm{Rb}+/-$ mouse models generated by homologous recombination do not develop retinoblastoma even after prolonged observations, perhaps suggesting differences in human and mouse $\mathrm{Rb}$ precursor cells.

In the majority of human trilateral retinoblastomas, the ocular tumors precede pineoblastoma. These observations suggest possible differences in the cell of origin or transformation events required for development of $\mathrm{RB}$ and pineoblastoma. The $\mathrm{Rb}+/-$ mice developed a high incidence of pituitary neoplasms after a prolonged latency, and RBdeficient embryos showed defective development of the hindbrain due to increased cell death. ${ }^{84}$ When $\mathrm{Rb}+/-$ mice are crossed with p53+/-, a variety of tumors develop, including pineoblastoma. Remarkably, in $\mathrm{Rb}+/-$, p53-/mice the incidence of pineoblastomas increased to $40 \%$, contrasted with $1 \%$ in the $\mathrm{Rb}+/-, \mathrm{p} 53+/-$ mice. ${ }^{171}$ These observations indicate that functional interactions and cooperative tumorigenic effects of $\mathrm{pRb}$ and $\mathrm{p} 53$ are important in the development of pineoblastoma. A requirement for concurrent inactivation of p53 and pRb may explain the relatively frequent development of pineal and midbrain PNETs in transgenic mice generated from viral oncogenes (described later) that are known to have $\mathrm{pRb}$ and $\mathrm{p} 53$ binding activity. Whether both $\mathrm{p} 53$ and pRb inactivation is required for development of human pineoblastomas is not known.

\section{Trilateral Rb in Transgenic Mice}

Tumors resembling pineoblastomas as well as midbrain PNETs are reported in several retinoblastoma transgenic mouse models driven by different viral oncogenes. In one model in which SV40 large T expression was driven by a Moloney murine sarcoma virus enhancer, pineal hyperplasia developed in adult mice culminating in highly infiltrative midbrain PNET-like tumors with accompanying 


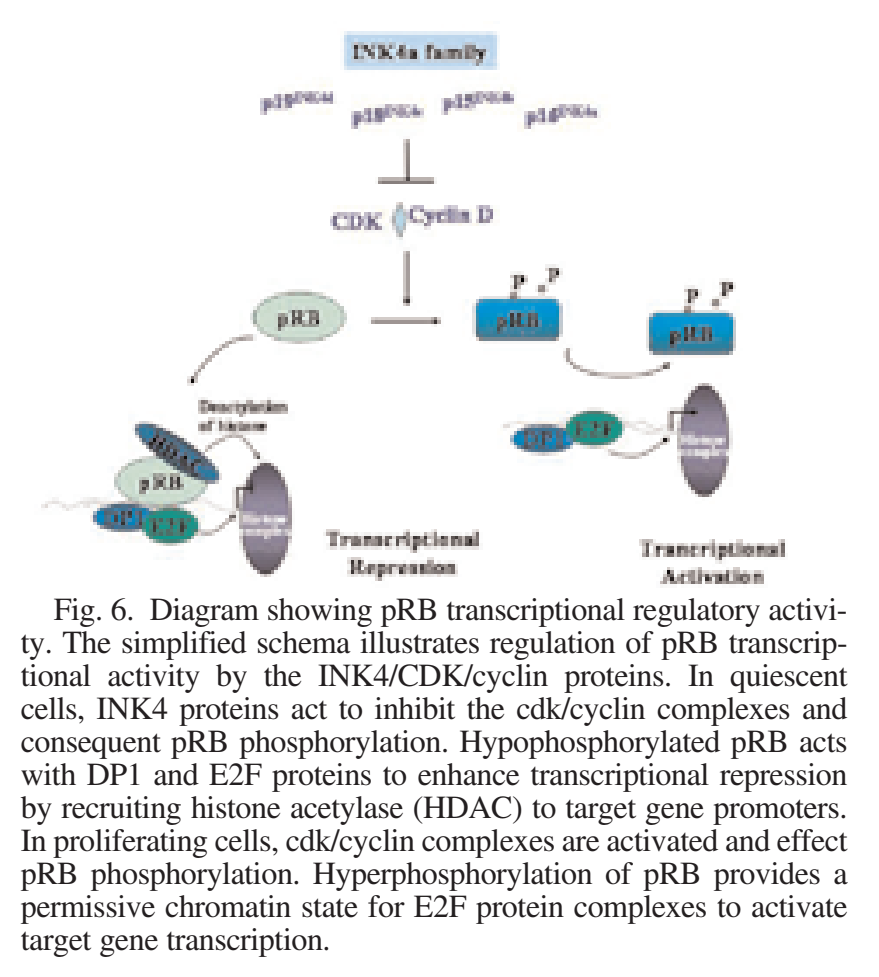

destruction of the pineal gland. The resulting tumors had poorly differentiated histological features with minimal expression of neuron-specific enolase and NF-H, but expressed $\mathrm{S}$ antigen, a marker characteristic for pinealocytes and rhodopsin, thus indicating a potential pineal origin for these midbrain tumors. ${ }^{96}$ Interestingly, there were no retinal tumors but instead the mice displayed heritable defects in lens fiber differentiation, retinal dysplasia, and pancreatic tumors. ${ }^{66} \mathrm{~A}$ second transgenic model more closely resembling human trilateral retinoblastoma with early-onset pineal PNET associated with retinoblastoma has been described in transgenic mice with SV40 expression targeted to photoreceptor cells by a murine interstitial retinol-binding protein promoter. Mice exhibited early pineal hyperplasia and both retinoblastoma-like and pineal tumors developed by the time they reached 2 weeks of age. ${ }^{76}$

Transgenic mice with PNET-like tumors of the diencephalon and/or midbrain regions in association with retinal tumors have also been generated using viral transgenes, and have been postulated to resemble the less frequent association of suprasellar and parasellar tumors in human trilateral retinoblastoma. Transgenic mice with targeted retinal expression of the SV40 large T antigen through a luteinizing hormone $\beta$ subunit promoter developed multifocal, bilateral retinoblastoma, and produced offspring with retinoblastoma and a high incidence (27\%) of midbrain tumors. ${ }^{107}$ The resulting primitive intracranial tumors were found to originate not from the pineal gland but from subependymal cells of the cerebral aqueduct. ${ }^{93}$ Similarly, al-Ubaidi, et al., ${ }^{2}$ found early development of retinal and brain tumors in a large number of transgenic mice in the embryonic and early postnatal stages, with targeted expression of SV40 large T antigen to rod and cone photoreceptors observed using the human interstitial retinol-binding protein promoter. Nevertheless, in contrast to pineal PNET in the murine interstitial retinol-binding protein-directed transgenic mice, primitive brain tumors with neuron-specific enolase and $\mathrm{S}$ antigen expression developed in the diencephalon, adjacent to the third ventricle.

The fidelity of viral oncogene-driven transgenic mouse models to human diseases is often limited by lack of promoter specificity. Nonetheless, these studies suggest that loss of $\mathrm{pRb}$ can lead to transformation of pineal precursor cells and progenitors in the subventricular germinal matrix. It is likely that loss of pRb and/or p53 occurs in sporadic human pineoblastoma or midbrain PNET; however, the extent of involvement and mechanisms of inactivation remain to be determined.

\section{Molecular Genetic Studies of Pineoblastoma}

It is not known whether direct mutations of $R B 1$ or alternate epigenetic mechanisms of $R B 1$ gene inactivation or functional pRB loss occur in sporadic pineoblastoma. Recent observations, which show significantly worse outcomes in patients with pineoblastoma associated with constitutional RB1 defects compared with sporadic pineoblastoma, ${ }^{126}$ suggest possible biological differences between these diseases. A number of explanations may underlie these observations, including possible differences in RB1 genotypephenotype correlations and involvement of distinct loci of origin in these diseases. Alternatively, the more aggressive disease course in pRB-associated pineoblastoma may reflect the greater genomic instability reported to occur with constitutional pRB loss. ${ }^{6}$ It is not known whether changes in chromosomes 1q31 and 6p22, which have been reported in $50 \%$ of human retinoblastoma, ${ }^{35,37}$ occur in PNETs associated or not associated with retinoblastoma.

To date only very limited cytogenetic and molecular data are available for this rare tumor. Informative karyotypic studies have been reported for seven cases of primary pineoblastoma; two of these were associated with trilateral retinoblastoma, and two were cell lines (Table 2). As with the cerebral supratentorial PNET, patients with cytogenetically normal karyotypes and isolated monosomy 22 (one case each) were identified. No consistent cytogenetic change can be inferred from these small numbers. Curiously, although pineoblastomas have been linked to hereditary retinoblastoma as part of the trilateral retinoblastoma complex, none of the sporadic cases of pineoblastoma exhibited a visible change in the region of the RB1 locus at chromosome $13 \mathrm{q} 14$.

The CGH profiles for pineoblastoma have so far only been reported collectively with cerebral supratentorial PNETs, and therefore pineoblastoma-specific information cannot be separately derived from the publications. Recently, in a CGH study of pineocytomas, intermediate (WHO Grade III) and high-grade (WHO Grade IV [pineoblastoma]) pineal parenchymal tumors ${ }^{137}$ it was reported that pineoblastomas exhibited an average of 5.6 chromosomal changes, in contrast with minimal to no changes in pineocytomas. High-level gains of chromosomes 1q, 5p and $\mathrm{q}, 6 \mathrm{p}$, and $14 \mathrm{q}$ were observed in pineoblastomas, which also frequently demonstrated monosomy 22 (two of three cases). In a recent microarray study, investigators attempted to identify genes that are differentially expressed between pineoblastoma and fetal pineal gland; however, the small number of tumors analyzed (two) significantly limits the interpretation of this study. ${ }^{33}$ 
Single-gene investigations of pineoblastoma have included five pineal tumors with negative results for $\mathrm{p} 53^{160}$ and Waf1/p21 ${ }^{161}$ gene aberrations. Biegel, et al., ${ }^{18}$ reported a missense INI1 mutation in a 7-month-old infant with a histologically confirmed pineoblastoma without rhabdoid features, and with monosomy 22 as the only abnormality. It is not known whether INI1 mutations are more likely to occur in pineoblastomas presenting in very young children with particularly aggressive disease. The recent development of INI1-specific antibodies ${ }^{89}$ should facilitate a broader scope of investigations into the genetic and functional role of the INI1 locus in the development of pineoblastoma.

\section{CONCLUSIONS}

Molecular genetic studies of supratentorial PNET and pineoblastoma are limited by the rare incidences of these tumors and the ongoing challenges in their histopathological diagnosis. Nonetheless, our review of existing clinical, molecular genetic, and relevant mouse studies implicates a role for the $\mathrm{pRB} / \mathrm{Ink} 4 / \mathrm{p} 53$ and DNA repair pathways in the development of supratentorial PNETs. Clearly, future concerted collaborative efforts, through dedicated and coordinated clinical, histopathological, and molecular studies are needed to identify the underlying molecular genetic defects involved in supratentorial PNET development. Such studies will be crucial for the development of appropriate disease models and more effective treatment regimens for these tumors.

\section{References}

1. Agamanolis DP, Malone JM: Chromosomal abnormalities in 47 pediatric brain tumors. Cancer Genet Cytogenet 81:125-134, 1995

2. al-Ubaidi MR, Font RL, Quiambao AB, et al: Bilateral retinal and brain tumors in transgenic mice expressing simian virus 40 large $\mathrm{T}$ antigen under control of the human interphotoreceptor retinoid-binding protein promoter. J Cell Biol 119:1681-1687, 1992

3. Albright AL, Wisoff JH, Zeltzer P, et al: Prognostic factors in children with supratentorial (nonpineal) primitive neuroectodermal tumors. A neurosurgical perspective from the Children's Cancer Group. Pediatr Neurosurg 22:1-7, 1995

4. Aldosari N, Bigner SH, Burger PC, et al: MYCC and MYCN oncogene amplification in medulloblastoma. A fluorescence in situ hybridization study on paraffin sections from the Children's Oncology Group. Arch Pathol Lab Med 126:540-544, 2002

5. Allenspach EJ, Maillard I, Aster JC, et al: Notch signaling in cancer. Cancer Biol Ther 1:466-476, 2002

6. Amare Kadam PS, Ghule P, Jose J, et al: Constitutional genomic instability, chromosome aberrations in tumor cells and retinoblastoma. Cancer Genet Cytogenet 150:33-43, 2004

7. Armstrong DD, Giangaspero F: Pediatric brain tumors: introduction. Brain Pathol 13:373-375, 2003

8. Avet-Loiseau H, Venuat AM, Terrier-Lacombe MJ, et al: Comparative genomic hybridization detects many recurrent imbalances in central nervous system primitive neuroectodermal tumors in children. Br J Cancer 79:1843-1847, 1999

9. Bader JL, Meadows AT, Zimmerman LE, et al: Bilateral retinoblastoma with ectopic intracranial retinoblastoma: trilateral retinoblastoma. Cancer Genet Cytogenet 5:203-213, 1982

10. Barker FG, Chen P, Furman F, et al: P16 deletion and mutation analysis in human brain tumors. J Neurooncol 31:17-23, 1997

11. Bayani J, Zielenska M, Marrano P, et al: Molecular cytogenetic analysis of medulloblastomas and supratentorial primitive neu- roectodermal tumors by using conventional banding, comparative genomic hybridization, and spectral karyotyping. J Neurosurg 93:437-448, 2000

12. Becker LE, Hinton D: Primitive neuroectodermal tumors of the central nervous system. Hum Pathol 14:538-550, 1983

13. Begemann M, Lyden D, Rosenblum MK, et al: Primary lepntomenaingeal primitive neuroectodermal tumor. J Neurooncol 63:299-303, 2003

14. Berger MS, Edwards MS, Wara WM, et al: Primary cerebral neuroblastoma. Long-term follow-up review and therapeutic guidelines. J Neurosurg 59:418-423, 1983

15. Bhattacharjee MB, Armstrong DD, Vogel H, et al: Cytogenetic analysis of 120 primary pediatric brain tumors and literature review. Cancer Genet Cytogenet 97:39-53, 1997

16. Biegel JA: Cytogenetics and molecular genetics of childhood brain tumors. Neuro-oncol 1:139-151, 1999

17. Biegel JA: Genetics of pediatric central nervous system tumors. J Pediatr Hematol Oncol 19:492-501, 1997

18. Biegel JA, Fogelgren B, Zhou JY, et al: Mutations of the INI1 rhabdoid tumor suppressor gene in medulloblastomas and primitive neuroectodermal tumors of the central nervous system. Clin Cancer Res 6:2759-2763, 2000

19. Biegel JA, Janss AJ, Raffel C, et al: Prognostic significance of chromosome $17 \mathrm{p}$ deletions in childhood primitive neuroectodermal tumors (medulloblastomas) of the central nervous system. Clin Cancer Res 3:473-478, 1997

20. Biegel JA, Rorke LB, Janss AJ, et al: Isochromosome 17q demonstrated by interphase fluorescence in situ hybridization in primitive neuroectodermal tumors of the central nervous system. Genes Chromosomes Cancer 14:85-96, 1995

21. Bigner SH, McLendon RE, Fuchs H, et al: Chromosomal characteristics of childhood brain tumors. Cancer Genet Cytogenet 97:125-134, 1997

22. Blach LE, McCormick B, Abramson DH, et al: Trilateral retinoblastoma-incidence and outcome: a decade of experience. Int J Radiat Oncol Biol Phys 29:729-733, 1994

23. Blaeker H, Rasheed BK, McLendon RE, et al: Microsatellite analysis of childhood brain tumors. Genes Chromosomes Cancer 15:54-63, 1996

24. Bossi G, Lapi E, Strano S, et al: Mutant p53 gain of function: reduction of tumor malignancy of human cancer cell lines through abrogation of mutant p53 expression. Oncogene:Epub ahead of print 19 Sep, 2005

25. Bourdon JC, Fernandes K, Murray-Zmijewski F, et al: p53 isoforms can regulate p53 transcriptional activity. Genes Dev 19: 2122-2137, 2005

26. Bourdon JC, Laurenzi VD, Melino G, et al: p53:25 years of research and more questions to answer. Cell Death Differ 10: 397-399, 2003

27. Brehm A, Miska EA, McCance DJ, et al: Retinoblastoma protein recruits histone deacetylase to repress transcription. Nature 391:597-601, 1998

28. Bremner R, Chen D, Pacal M, et al: The RB protein family in retinal development and retinoblastoma: new insights from new mouse models. Dev Neurosci 26:417-434, 2004

29. Brockmeyer DL, Walker ML, Thompson G, et al: Astrocytoma and pineoblastoma arising sequentially in the fourth ventricle of the same patient. Case report and molecular analysis. Pediatr Neurosurg 26:36-40, 1997

30. Burnett ME, White EC, Sih S, et al: Chromosome arm 17p deletion analysis reveals molecular genetic heterogeneity in supratentorial and infratentorial primitive neuroectodermal tumors of the central nervous system. Cancer Genet Cytogenet 97:25-31, 1997

31. Burns AS, Jaros E, Cole M, et al: The molecular pathology of p53 in primitive neuroectodermal tumors of the central nervous system. Br J Cancer 86:1117-1123, 2002

32. Chadduck WM, Boop FA, Sawyer JR: Cytogenetic studies of pediatric brain and spinal cord tumors. Pediatr Neurosurg 17: 57-65, 1991-1992 
33. Champier J, Jouvet A, Rey C, et al: Identification of differentially expressed genes in human pineal parenchymal tumors by microarray analysis. Acta Neuropathol (Berl) 109:306-313, 2005

34. Chen AY, Lee H, Hartman J, et al: Secondary supratentorial primitive neuroectodermal tumor following irradiation in a patient with low-grade astrocytoma. AJNR Am J Neuroradiol 26: 160-162, 2005

35. Chen D, Gallie BL, Squire JA: Minimal regions of chromosomal imbalance in retinoblastoma detected by comparative genomic hybridization. Cancer Genet Cytogenet 129:57-63, 2001

36. Chen D, Livne-bar I, Vanderluit JL, et al: Cell-specific effects of RB or RB/p107 loss on retinal development implicate an intrinsically death-resistant cell-of-origin in retinoblastoma. Cancer Cell 5:539-551, 2004

37. Chen D, Pajovic S, Duckett A, et al: Genomic amplification in retinoblastoma narrowed to 0.6 megabase on chromosome $6 \mathrm{p}$ containing a kinesin-like gene, RBKIN. Cancer Res 62:967-971, 2002

38. Chen H, Thiagalingam A, Chopra H, et al: Conservation of the Drosophila lateral inhibition pathway in human lung cancer: a hairy-related protein (HES-1) directly represses achaete-scute homolog-1 expression. Proc Natl Acad Sci U S A 94: 5355-5360, 1997

39. Chung SK, Wang KC, Nam DH, et al: Brain tumor in the first year of life: a single institute study. J Korean Med Sci 13:65-70, 1998

40. Cohen BH, Zeltzer PM, Boyett JM, et al: Prognostic factors and treatment results for supratentorial primitive neuroectodermal tumors in children using radiation and chemotherapy: a Childrens Cancer Group randomized trial. J Clin Oncol 13:1687-1696, 1995

41. Cooper IS, Kernohan JW: Heterotopic glial nests in the subarachnoid space; histopathologic characteristics, mode of origin and relation to meningeal gliomas. J Neuropathol Exp Neurol 10:16-29, 1951

42. Coskun V, Luskin MB: The expression pattern of the cell cycle inhibitor $\mathrm{p} 19^{\mathrm{INK} 4 \mathrm{~d}}$ by progenitor cells of the rat embryonic telencephalon and neonatal anterior subventricular zone. J Neurosci 21:3092-3103, 2001

43. Dahmane N, Sanchez P, Gitton Y, et al: The Sonic HedgehogGli pathway regulates dorsal brain growth and tumorigenesis. Development 128:5201-5212, 2001

44. Dai AI, Backstrom JW, Burger PC, et al: Supratentorial primitive neuroectodermal tumors of infancy: clinical and radiologic findings. Pediatr Neurol 29:430-434, 2003

45. Davies JJ, Wilson IM, Lam WL: Array CGH technologies and their applications to cancer genomes. Chromosome Res 13:237-248, 2005

46. De Vos M, Hayward BE, Picton S, et al: Novel PMS2 pseudogenes can conceal recessive mutations causing a distinctive childhood cancer syndrome. Am J Hum Genet 74:954-964, 2004

47. Dirks PB, Harris L, Hoffman HJ, et al: Supratentorial primitive neuroectodermal tumors in children. J Neurooncol 29:75-84, 1996

48. Dockhorn-Dworniczak B, Wolff J, Poremba C, et al: A new germline TP53 gene mutation in a family with Li-Fraumeni syndrome. Eur J Cancer 32A:1359-1365, 1996

49. Donehower LA, Harvey M, Slagle BL, et al: Mice deficient for p53 are developmentally normal but susceptible to spontaneous tumors. Nature 356:215-221, 1992

50. Dorfmuller G, Wurtz FG, Kleinert R, et al: Cerebral primitive neuro-ectodermal tumor following treatment of a unilateral retinoblastoma. Acta Neurochir (Wien) 139:749-755, 1997

51. Eberhart CG, Chaudhry A, Daniel RW, et al: Increased p53 immunopositivity in anaplastic medulloblastoma and supratentorial PNET is not caused by JC virus. BMC Cancer 5:19, 2005

52. Eberhart CG, Kratz J, Wang Y, et al: Histopathological and molecular prognostic markers in medulloblastoma: c-myc, N-myc,
TrkC, and anaplasia. J Neuropathol Exp Neurol 63:441-449, 2004

53. Elias WJ, Lopes MB, Golden WL, et al: Trilateral retinoblastoma variant indicative of the relevance of the retinoblastoma tumor-suppressor pathway to medulloblastomas in humans. J Neurosurg 95:871-878, 2001

54. Fan X, Mikolaenko I, Elhassan I, et al: Notch1 and notch2 have opposite effects on embryonal brain tumor growth. Cancer Res 64:7787-7793, 2004

55. Fan X, Wang Y, Kratz J, et al: hTERT gene amplification and increased mRNA expression in central nervous system embryonal tumors. Am J Pathol 162:1763-1769, 2003

56. Felix CA, Slave I, Dunn M, et al: p53 gene mutations in pediatric brain tumors. Med Pediatr Oncol 25:431-436, 1995

57. Finelli DA, Shurin SB, Bardenstein DS: Trilateral retinoblastoma: two variations. AJNR Am J Neuroradiol 16:166-170, 1995

58. Frank AJ, Hernan R, Hollander A, et al: The TP53-aRF tumor suppressor pathway is frequently disrupted in large/cell anaplastic medulloblastoma. Brain Res Mol Brain Res 121:137-140, 2004

59. Friend SH, Bernards R, Rogelj S, et al: A human DNA segment with properties of the gene that predisposes to retinoblastoma and osteosarcoma. Nature 323:643-646, 1986

60. Fruhwald MC, O'Dorisio MS, Dai Z, et al: Aberrant hypermethylation of the major breakpoint cluster region in $17 \mathrm{p} 11.2$ in medulloblastomas but not supratentorial PNETs. Genes Chromosomes Cancer 30:38-47, 2001

61. Fujii Y, Hongo T, Hayashi Y: Chromosome analysis of brain tumors in childhood. Genes Chromosomes Cancer 11:205-215, 1994

62. Fults D, Pedone CA, Morse HG, et al: Establishment and characterization of a human primitive neuroectodermal tumor cell line from the cerebral hemisphere. J Neuropathol Exp Neurol 51:272-280, 1992

63. Geyer JR, Zeltzer PM, Boyett JM, et al: Survival of infants with primitive neuroectodermal tumors or malignant ependymomas of the CNS treated with eight drugs in 1 day: a report from the Childrens Cancer Group. J Clin Oncol 12:1607-1615, 1994

64. Girschick HJ, Klein R, Scheurlen WG, et al: Cytogenetic and histopathologic studies of congenital supratentorial primitive neuroectodermal tumors: a case report. Pathol Oncol Res 7:67-71, 2001

65. Goodrich LV, Milenkovic L, Higgins KM, et al: Altered neural cell fates and medulloblastoma in mouse patched mutants. Science 277:1109-1113, 1997

66. Gotz W, Schucht C, Roth J, et al: Endocrine pancreatic tumors in MSV-SV40 large T transgenic mice. Am J Pathol 142: 1493-1503, 1993

67. Grotzer MA, Janss AJ, Fung K, et al: TrkC expression predicts good clinical outcome in primitive neuroectodermal brain tumors. J Clin Oncol 18:1027-1035, 2000

68. Guan KL, Jenkins CW, Li Y, et al: Isolation and characterization of p19INK4d, a p16-related inhibitor specific to CDK6 and CDK4. Mol Biol Cell 7:57-70, 1996

69. Hader WJ, Drovini-Zis K, Maguire JA: Primitive neuroectodermal tumors in the central nervous system following cranial irradiation: a report of four cases. Cancer 97:1072-1076, 2003

70. Hallahan AR, Pritchard JI, Hansen S, et al: The SmoA1 mouse model reveals that notch signaling is critical for the growth and survival of sonic hedgehog-induced medulloblastomas. Cancer Res 64:7794-7800, 2004

71. Hamilton SR, Liu B, Parsons RE, et al: The molecular basis of Turcot's syndrome. N Engl J Med 332:839-847, 1995

72. Hatakeyama M, Weinberg RA: The role of RB in cell cycle control. Prog Cell Cycle Res 1:9-19, 1995

73. He TC, Sparks AB, Rago C, et al: Identification of c-MYC as a target of the APC pathway. Science 281:1509-1512, 1998

74. Ho YS, Hsieh LL, Chen JS, et al: p53 gene mutation in cerebral 
primitive neuroectodermal tumor in Taiwan. Cancer Lett 104: 103-113, 1996

75. Hong TS, Mehta MP, Boyett JM, et al: Patterns of failure in supratentorial primitive neuroectodermal tumors treated in Children's Cancer Group Study 921, a phase III combined modality study. Int J Radiat Oncol Biol Phys 60:204-213, 2004

76. Howes KA, Lasudry JG, Albert DM, et al: Photoreceptor cell tumors in transgenic mice. Invest Ophthalmol Vis Sci 35: 342-351, 1994

77. Hu QJ, Dyson N, Harlow E: The regions of the retinoblastoma protein needed for binding to adenovirus E1A or SV40 large T antigen are common sites for mutations. EMBO J 9:1147-1155, 1990

78. Huang H, Mahler-Araujo BM, Sankila A, et al: APC mutations in sporadic medulloblastomas. Am J Pathol 156:433-437, 2000

79. Ikeda J, Sawamura Y, van Meir EG: Pineoblastoma presenting in familial adenomatous polyposis (FAP): random association, FAP variant or Turcot syndrome? Br J Neurosurg 12:576-578, 1998

80. Imbalzano AN, Jones SN: Snf5 tumor suppressor couples chromatin remodeling, checkpoint control, and chromosomal stability. Cancer Cell 7:294-295, 2005

81. Inda MM, Mercapide J, Munoz J, et al: PTEN and DMBT1 homozygous deletion and expression in medulloblastomas and supratentorial primitive neuroectodermal tumors. Oncol Rep 12:1341-1347, 2004

82. Irwin MS, Kaelin WG Jr: Role of the newer p53 family proteins in malignancy. Apoptosis 6:17-29, 2001

83. Ishibashi M, Moriyoshi K, Sasai Y, et al: Persistent expression of helix-loop-helix factor HES-1 prevents mammalian neural differentiation in the central nervous system. EMBO J 13:1799-1805, 1994

84. Jacks T, Fazeli A, Schmitt EM, et al: Effects of an Rb mutation in the mouse. Nature 359:295-300, 1992

85. Jakacki RI: Pineal and nonpineal supratentorial primitive neuroectodermal tumors. Childs Nerv Syst 15:586-591, 1999

86. Jakacki RI, Zeltzer PM, Boyett JM, et al: Survival and prognostic factors following radiation and/or chemotherapy for primitive neuroectodermal tumors of the pineal region in infants and children: a report of the Childrens Cancer Group. J Clin Oncol 13:1377-1383, 1995

87. Jaros E, Lunec J, Perry RH, et al: p53 protein overexpression identifies a group of central primitive neuroectodermal tumors with poor prognosis. Br J Cancer 68:801-807, 1993

88. Jensen RD, Miller RW: Retinoblastoma: epidemiologic characteristics. N Engl J Med 285:307-311, 1971

89. Judkins AR, Mauger J, Ht A, et al: Immunohistochemical analysis of hSNF5/INI1 in pediatric CNS neoplasms. Am J Surg Pathol 28:644-650, 2004

90. Kees UR, Biegel JA, Ford J, et al: Enhanced MYCN expression and isochromosome $17 \mathrm{q}$ in pineoblastoma cell lines. Genes Chromosomes Cancer 9:129-135, 1994

91. Kim DG, Lee DY, Paek SH, et al: Supratentorial primitive neuroectodermal tumors in adults. J Neurooncol 60:43-52, 2002

92. Kivela T: Trilateral retinoblastoma: a meta-analysis of hereditary retinoblastoma associated with primary ectopic intracranial retinoblastoma. J Clin Oncol 17:1829-1837, 1999

93. Kivela T, Virtanen I, Marcus DM, et al: Neuronal and glial properties of a murine transgenic retinoblastoma model. Am J Pathol 138:1135-1148, 1991

94. Kleihues P, Zuulch KJ: Brain Tumours: Their Biology and Pathology, ed 3. Berlin: Springer-Verlag, 1986

95. Koch A, Waha A, Tonn JC, et al: Somatic mutations of WNT/wingless signaling pathway components in primitive neuroectodermal tumors. Int J Cancer 93:445-449, 2001

96. Korf HW, Gotz W, Herken R, et al: S-antigen and rod-opsin immunoreactions in midline brain neoplasms of transgenic mice: similarities to pineal cell tumors and certain medulloblastomas in man. J Neuropathol Exp Neurol 49:424-437, 1990

97. Kouyialis AT, Boviatsis EI, Karampelas IK, et al: Primitive supratentorial neuroectodermal tumor in an adult. J Clin Neurosci 12:492-495, 2005

98. Kraus JA, Felsberg J, Tonn JC, et al: Molecular genetic analysis of the TP53, PTEN, CDKN2A, EGFR, CDK4 and MDM2 tumor-associated genes in supratentorial primitive neuroectodermal tumors and glioblastomas of childhood. Neuropathol Appl Neurobiol 28:325-333, 2002

99. Kraus JA, Oster C, Sorensen N, et al: Human medulloblastomas lack point mutations and homozygous deletions of the hSNF5/INII tumor suppressor gene. Neuropathol Appl Neurobiol 28: 136-141, 2002

100. Lee WH, Bookstein R, Hong F, et al: Human retinoblastoma susceptibility gene: cloning, identification, and sequence. Science 235:1394-1399, 1987

101. Lesnick JE, Chayt KJ, Bruce DA, et al: Familial pineoblastoma. Report of two cases. J Neurosurg 62:930-932, 1985

102. Leung W, Ribeiro RC, Hudson M, et al: Second malignancy after treatment of childhood acute myeloid leukemia. Leukemia 15:41-45, 2001

103. Luo RX, Postigo AA, Dean DC: Rb interacts with histone deacetylase to repress transcription. Cell 92:463-473, 1998

104. Magnaghi-Jaulin L, Groisman R, Naguibneva I, et al: Retinoblastoma protein represses transcription by recruiting a histone deacetylase. Nature 391:601-605, 1998

105. Malkin D, Li FP, Strong LC, et al: Germ line p53 mutations in a familial syndrome of breast cancer, sarcomas, and other neoplasms. Science 250:1233-1238, 1990

106. Marcus DM, Brooks SE, Leff G, et al: Trilateral retinoblastoma: insights into histogenesis and management. Surv Ophthalmol 43:59-70, 1998

107. Marcus DM, Carpenter JL, O'Brien JM, et al: Primitive neuroectodermal tumor of the midbrain in a murine model of retinoblastoma. Invest Ophthalmol Vis Sci 32:293-301, 1991

108. Marec-Berard P, Jouvet A, Thiesse P, et al: Supratentorial embryonal tumors in children under 5 years of age: an SFOP study of treatment with postoperative chemotherapy alone. Med Pediatr Oncol 38:83-90, 2002

109. McLendon RE, Burger PC: The primitive neuroectodermal tumor: A cautionary view. J Pediatric Neurosciences 3:1-8, 1987

110. Mena H, Nakazato Y, Jouvet A, et al: Pineoblastoma, in Kleihues P, Cavenee WK (eds): World Health Organization Classification of Tumours. Pathology and Genetics of Tumours of the Nervous System. Lyon: IARC Press, 2000

111. Mena H, Rushing EJ, Ribas JL, et al: Tumors of pineal parenchymal cells: a correlation of histological features, including nucleolar organizer regions, with survival in 35 cases. Hum Pathol 26:20-30, 1995

112. Moriuchi S, Shimizu K, Miyao Y, et al: An immunohistochemical analysis of medulloblastoma and PNET with emphasis on N-myc protein expression. Anticancer Res 16:2687-2692, 1996

113. Moss SD, Haines SJ, Leonard AS, et al: Congenital supratentorial and infratentorial peripheral neurogenic tumor: a clinical, ultrastructural, and immunohistochemical study. Neurosurgery 19:426-433, 1986

114. Nakagawa H, Lockman JC, Frankel WL, et al: Mismatch repair gene $P M S 2$ : disease-causing germline mutations are frequent in patients whose tumors stain negative for PMS2 protein, but paralogous genes obscure mutation detection and interpretation. Cancer Res 64:4721-4727, 2004

115. Nicholson JC, Ross FM, Kohler JA, et al: Comparative genomic hybridization and histological variation in primitive neuroectodermal tumors. Br J Cancer 80:1322-1331, 1999

116. Nishio S, Morioka T, Suzuki S, et al: Supratentorial primitive neuroectodermal tumors: a report of four cases with an unusual clinical course in one patient. Acta Neurochir (Wien) 140: 207-213, 1998

117. Ohtsuka T, Sakamoto M, Guillemot F, et al: Roles of the basic 
helix-loop-helix genes Hes1 and Hes5 in expansion of neural stem cells of the developing brain. J Biol Chem 276: 30467-30474, 2001

118. Okazaki T, Kitano K, Uchiyama I, et al: p53mdb: p53 mutation database, in Miyano S, Takagi T (eds): Proceedings of the 8th Workshop on Genome Informatics. Tokyo: Universal Academy Press, 1997, pp 324-325

119. Orellana C, Martinez F, Hernandez-Marti M, et al: A novel TP53 germ-line mutation identified in a girl with a primitive neuroectodermal tumor and her father. Cancer Genet Cytogenet 105:103-108, 1998

120. Ortega S, Malumbres M, Barbacid M: Cyclin D-dependent kinases, INK4 inhibitors and cancer. Biochim Biophys Acta 1602:73-87, 2002

121. Pang JC, Chang Q, Chung YF, et al: Epigenetic inactivation of DLC-1 in supratentorial primitive neuroectodermal tumor. Hum Pathol 36:36-43, 2005

122. Paulino AC: Trilateral retinoblastoma: is the location of the intracranial tumor important? Cancer 86:135-141, 1999

123. Paulino AC, Melian E: Medulloblastoma and supratentorial primitive neuroectodermal tumors: an institutional experience. Cancer 86:142-148, 1999

124. Petronio J, He J, Fults D, et al: Common alternative gene alterations in adult malignant astrocytomas, but not in childhood primitive neuroectodermal tumors: P 16ink4 homozygous deletions and CDK4 gene amplifications. J Neurosurg 84: 1020-1023, 1996

125. Phelps WC, Yee CL, Munger K, et al: The human papillomavirus type 16 E7 gene encodes transactivation and transformation functions similar to those of adenovirus E1A. Cell 53:539-547, 1988

126. Plowman PN, Pizer B, Kingston JE: Pineal parenchymal tumors: II. On the aggressive behavior of pineoblastoma in patients with an inherited mutation of the RB1 gene. Clin Oncol (R Coll Radiol) 16:244-247, 2004

127. Pomeroy SL, Tamayo P, Gaasenbeek M, et al: Prediction of central nervous system embryonal tumor outcome based on gene expression. Nature 415:436-442, 2002

128. Portwine C, Chilton-MacNeill S, Brown C, et al: Absence of germline and somatic p53 alterations in children with sporadic brain tumors. J Neurooncol 52:227-235, 2001

129. Postovsky S, Ben Arush MW, Elhasid R, et al: A novel case of a CAT to AAT transversion in codon 179 of the p53 gene in a supratentorial primitive neuroectodermal tumor harbored by a young girl. Case report and review of the literature. Oncology 65:46-51, 2003

130. Prebble E, Dyer S, Brundler M, Ellison D, et al: Genomic Imbalances in supratentorial primitive neuroectodermal tumors (STPNETS), in Abstracts from the 11th International Symposium on Pediatric Neuro-Oncology. Neuro-oncology 6:413, 2004 (Abstract)

131. Raffel C, Gilles FE, Weinberg KI: Reduction to homozygosity and gene amplification in central nervous system primitive neuroectodermal tumors of childhood. Cancer Res 50:587-591, 1990

132. Raffel C, McComb JG, Bodner S, et al: Benign brain stem lesions in pediatric patients with neurofibromatosis: case reports. Neurosurgery 25:959-964, 1989

133. Raffel C, Thomas GA, Tishler DM, et al: Absence of p53 mutations in childhood central nervous system primitive neuroectodermal tumors. Neurosurgery 33:301-306, 1993

134. Ray A, Ho M, Ma J, et al: A clinicobiological model predicting survival in medulloblastoma. Clin Cancer Res 10:7613-7620, 2004

135. Reddy AT, Janss AJ, Phillips PC, et al: Outcome for children with supratentorial primitive neuroectodermal tumors treated with surgery, radiation, and chemotherapy. Cancer 88: 2189-2193, 2000

136. Reifenberger J, Wolter M, Weber RG, et al: Missense muta- tions in $\mathrm{SMOH}$ in sporadic basal cell carcinomas of the skin and primitive neuroectodermal tumors of the central nervous system. Cancer Res 58:1798-1803, 1998

137. Rickert CH, Simon R, Bergmann M, et al: Comparative genomic hybridization in pineal parenchymal tumors. Genes Chromosomes Cancer 30:99-104, 2001

138. Rickert CH, Strater R, Kaatsch P, et al: Pediatric high-grade astrocytomas show chromosomal imbalances distinct from adult cases. Am J Pathol 158:1525-1532, 2001

139. Roberts P, Chumas PD, Picton S, et al: A review of the cytogenetics of 58 pediatric brain tumors. Cancer Genet Cytogenet 131:1-12, 2001

140. Rorke LB: Classification and grading of childhood brain tumors. Overview and statement of the problem. Cancer 56 (Suppl 7):1848-1849, 1985

141. Rorke LB, Biegel JA: Atypical teratoid/rhabdoid tumors, in Kleihues P, Cavanee W (eds): Pathology and Genetics of Tumours of the Nervous System. Lyon: IARC Press, 1997, pp 145-148

142. Rorke LB, Hart MN, Mclendon RE: Supratentorial primitive neuroectodermal tumor (PNET), in Kleihaues P, Cavenee W (eds): Pathology and Genetics of Tumours of the Nervous System. Lyon: IARC Press, 1997, p 141

143. Rostomily RC, Bermingham-McDonogh O, Berger MS, et al: Expression of neurogenic basic helix-loop-helix genes in primitive neuroectodermal tumors. Cancer Res 57:3526-3531, 1997

144. Roussel MF: The INK4 family of cell cycle inhibitors in cancer. Oncogene 18:5311-5317, 1999

145. Russell DS, Rubenstein LJ (eds): Pathology of Tumors of the Nervous System, ed 5. Baltimore: Williams and Wilkins, 1989, pp 380-394

146. Russo C, Pellarin M, Tingby O, et al: Comparative genomic hybridization in patients with supratentorial and infratentorial primitive neuroectodermal tumors. Cancer 86:331-339, 1999

147. Sato K, Schauble B, Kleihues $P$, et al: Infrequent alterations of the p15, p16, CDK4 and cyclin D1 genes in non-astrocytic human brain tumors. Int J Cancer 66:305-308, 1996

148. Senba S, Konishi F, Okamoto T, et al: Clinicopathologic and genetic features of nonfamilial colorectal carcinomas with DNA replication errors. Cancer 82:279-285, 1998

149. Sevenet N, Lellouch-Tubiana A, Schofield D, et al: Spectrum of $h S N F 5 / I N I 1$ somatic mutations in human cancer and genotype-phenotype correlations. Hum Mol Genet 8:2359-2368, 1999

150. Sévenet N, Sheridan E, Amram D, et al: Constitutional mutations of the $h S N F 5 / I N I 1$ gene predispose to a variety of cancers. Am J Hum Genet 65:1342-1348, 1999

151. Sherr CJ: The Pezcoller lecture: cancer cell cycles revisited. Cancer Res 60:3689-3695, 2000

152. Singh M, Krajewski M, Mikolajka A, et al: Molecular determinants for the complex formation between the retinoblastoma protein and LXCXE sequences. J Biol Chem:Epub ahead of print, 23 Aug 2005

153. Sriuranpong V, Borges MW, Strock CL, et al: Notch signaling induces rapid degradation of achaete-scute homolog 1. Mol Cell Biol 22:3129-3139, 2002

154. Stewart CL, Soria AM, Hamel PA: Integration of the $p R B$ and p53 cell cycle control pathways. J Neurooncol 51:183-204, 2001

155. Takeuchi H, Kubota T, Sato K, et al: Atypical neuronal-glial tumors of cerebral hemispheres in adults with PNET-like component: clinicopathological features of 5 cases. Clin Neuropathol 22:47-56, 2003

156. Taylor MD, Mainprize TG, Rutka JT: Molecular insight into medulloblastoma and central nervous system primitive neuroectodermal tumor biology from hereditary syndromes: a review. Neurosurgery 47:888-901, 2000

157. Timmermann B, Kortmann RD, Kuhl J, et al: Role of radiotherapy in the treatment of supratentorial primitive neuroectodermal 


\section{Molecular genetics of supratentorial PNETs and pineoblastomas}

tumors in childhood: results of the prospective German brain tumor trials HIT 88/89 and 91. J Clin Oncol 20:842-849, 2002

158. Tong WM, Ohgaki H, Huang H, et al: Null mutation of DNA strand break-binding molecule poly(ADP-ribose) polymerase causes medulloblastomas in p53 $3^{-1-}$ mice. Am J Pathol 162: 343-352, 2003

159. Trojanowski JQ, Tohyama T, Lee VM: Medulloblastomas and related primitive neuroectodermal brain tumors of childhood recapitulate molecular milestones in the maturation of neuroblasts. Mol Chem Neuropathol 17:121-135, 1992

160. Tsumanuma I, Sato M, Okazaki H, et al: The analysis of p53 tumor suppressor gene in pineal parenchymal tumors. Noshuyo Byori 12:39-43, 1995

161. Tsumanuma I, Tanaka R, Abe S, et al: Infrequent mutation of Waf1/p21 gene, a CDK inhibitor gene, in brain tumors. Neurol Med Chir 37:150-157, 1997

162. Uematsu Y, Takehara R, Shimizu M, et al: Pleomorphic primitive neuroectodermal tumor with glial and neuronal differentiation: clinical, pathological, cultural, and chromosomal analysis of a case. J Neurooncol 59:71-79, 2002

163. Vogelstein B, Lane D, Levine AJ: Surfing the p53 network. Nature 408:307-310, 2000

164. Vorechovsky I, Tingby O, Hartman M, et al: Somatic mutations in the human homologue of Drosophila patched in primitive neuroectodermal tumors. Oncogene 15:361-366, 1997

165. Waldbaur H, Gottschaldt M, Schmidt H, et al: [Medulloblastoma and pineoblastoma in monozygous twins (author's transl).] Klin Padiatr 188:366-371, 1976 (Ger)

166. Weber RG, Bridger JM, Benner A, et al: Centrosome amplification as a possible mechanism for numerical chromosome aberrations in cerebral primitive neuroectodermal tumors with TP53 mutations. Cytogenet Cell Genet 83:266-269, 1998

167. Weinberg RA: The retinoblastoma protein and cell cycle control. Cell 81:323-330, 1995

168. Weintraub SJ, Prater CA, Dean DC: Retinoblastoma protein switches the E2F site from positive to negative element. Nature 358:259-261, 1992

169. Wetmore C, Eberhart DE, Curran T: Loss of $p 53$ but not $A R F$ accelerates medulloblastoma in mice heterozygous for patched. Cancer Res 61:513-516, 2001

170. Whittle IR, McClellan K, Martin FJ, et al: Concurrent pineoblastoma and unilateral retinoblastoma: a forme fruste of trilateral retinoblastoma? Neurosurgery 17:500-505, 1985
171. Williams BO, Remington L, Albert DM, et al: Cooperative tumorigenic effects of germline mutations in $\mathrm{Rb}$ and p53. Nat Genet 7:480-484, 1994

172. Wolter M, Reifenberger J, Sommer C, et al: Mutations in the human homologue of the Drosophila segment polarity gene patched (PTCH) in sporadic basal cell carcinomas of the skin and primitive neuroectodermal tumors of the central nervous system. Cancer Res 57:2581-2585, 1997

173. Wolter M, Scharwachter C, Reifenberger J, et al: Absence of detectable alterations in the putative tumor suppressor gene $B T R C$ in cerebellar medulloblastomas and cutaneous basal cell carcinomas. Acta Neuropathol 106:287-290, 2003

174. Woodburn RT, Azzarelli B, Montebello JF, et al: Intense p53 staining is a valuable prognostic indicator for poor prognosis in medulloblastoma/central nervous system primitive neuroectodermal tumors. J Neurooncol 52:57-62, 2001

175. Zakrzewska M, Rieske P, Debiec-Rychter M, et al: Molecular abnormalities in pediatric embryonal brain tumors-analysis of loss of heterozygosity on chromosomes $1,5,9,10,11,16$, 17 and 22. Clin Neuropathol 23:209-217, 2004

176. Zindy F, Cunningham JJ, Sherr CJ, et al: Postnatal neuronal proliferation in mice lacking Ink4d and Kip1 inhibitors of cyclindependent kinases. Proc Natl Acad Sci U S A 96:13462-13467, 1999

177. Zindy F, Nilsson LM, Nguyen L, et al: Hemangiosarcomas, medulloblastomas, and other tumors in Ink4c/p53-null mice. Cancer Res 63:5420-5427, 2003

178. Zurawel RH, Chiappa SA, Allen C, et al: Sporadic medulloblastomas contain oncogenic beta-catenin mutations. Cancer Res 58:896-899, 1998

Manuscript received October 7, 2005.

Accepted in final form October 20, 2005.

Financial support was received from B.R.A.I.N. Child and is gratefully acknowledged. Dr. Huang is supported by a clinician scientist award from Cancer Care Ontario, Eli Lilly, and the Canadian Institute of Health Research.

Address reprint requests to: Annie Huang, M.D., Ph.D., Division of Hematology-Oncology, Hospital for Sick Children, 555 University Avenue, Toronto, Ontario, M5G 1X8 Canada. email: annie. huang@sickkids.ca. 